OPEN ACCESS

Edited by:

Anton Nijholt,

University of Twente, Netherlands

Reviewed by:

Robby Van Delden,

University of Twente, Netherlands António Fernando Coelho,

University of Porto, Portugal

${ }^{*}$ Correspondence:

Danica Mast

d.mast@hhs.n

d.mast@liacs.leidenuniv.nI

Specialty section:

This article was submitted to

Human-Media Interaction,

a section of the journal

Frontiers in Computer Science

Received: 28 February 2021

Accepted: 04 May 2021

Published: 04 June 2021

Citation:

Mast D, de Vries SI, Broekens J and Verbeek FJ (2021) The Participant Journey Map: Understanding the Design of Interactive Augmented

Play Spaces.

Front. Comput. Sci. 3:674132 doi: 10.3389/fcomp.2021.674132

\section{The Participant Journey Map: Understanding the Design of Interactive Augmented Play Spaces}

\author{
Danica Mast ${ }^{1,2,3 *}$, Sanne I. de Vries ${ }^{1}$, Joost Broekens ${ }^{3}$ and Fons J. Verbeek ${ }^{3}$ \\ ${ }^{1}$ Research Group Healthy Lifestyle in a Supporting Environment, Centre of Expertise Health Innovation, The Hague University of \\ Applied Sciences, The Hague, Netherlands, ${ }^{2}$ User Experience Design, Communication and Multimedia Design, Faculty for IT and \\ Design, The Hague University of Applied Sciences, The Hague, Netherlands, ${ }^{3}$ Leiden Institute of Advanced Computer Science, \\ Leiden University, Leiden, Netherlands
}

Augmented Play Spaces (APS) are (semi-) public environments where playful interaction is facilitated by enriching the existing environment with interactive technology. APS can potentially facilitate social interaction and physical activity in (semi-)public environments. In controlled settings APS show promising effects. However, people's willingness to engage with APS in situ, depends on many factors that do not occur in aforementioned controlled settings (where participation is obvious). To be able to achieve and demonstrate the positive effects of APS when implemented in (semi-)public environments, it is important to gain more insight in how to motivate people to engage with them and better understand when and how those decisions can be influenced by certain (design) factors. The Participant Journey Map (PJM) was developed following multiple iterations. First, based on related work, and insights gained from previously developed and implemented APS, a concept of the PJM was developed. Next, to validate and refine the PJM, interviews with 6 experts with extensive experience with developing and implementing APS were conducted. The first part of these interviews focused on influential (design) factors for engaging people into APS. In the second part, experts were asked to provide feedback on the first concept of the PJM. Based on the insights from the expert interviews, the PJM was adjusted and refined. The Participant Journey Map consists of four layers: Phases, States, Transitions and Influential Factors. There are two overarching phases: 'Onboarding' and 'Participation' and 6 states a (potential) participant goes through when engaging with an APS: 'Transit,' 'Awareness,' 'Interest,' 'Intention,' 'Participation,' 'Finishing.' Transitions indicate movements between states. Influential factors are the factors that influence these transitions. The PJM supports directions for further research and the design and implementation of APS. It contributes to previous work by providing a detailed overview of a participant journey and the factors that influence motivation to engage with APS. Notable additions are the detailed overview of influential factors, the introduction of the states 'Awareness,' 'Intention' and 'Finishing' and the non-linear approach. This will support taking into account these often overlooked, key moments in future APS research and design projects. Additionally, suggestions for future research into the design of APS are given. 
Keywords: augmented play spaces, playful interaction, urban interfaces, spatial augmented reality, user journey map, user experience design

\section{INTRODUCTION}

Augmented play spaces (APS) are (semi-) public environments where playful interaction is facilitated by enriching the existing environment with interactive technology. This can be facilitated by screens, projections (Gómez-Maureira, 2014; van Delden et al., 2017; Mast, 2019) and light, but also through sound (Schraffenberger and Van Der Heide, 2014), movement and other sensory perceptible manifestations. APS are also known as Co-located Augmented Play-spaces (CAPs) (van Delden et al., 2018), interactive play systems (van Delden et al., 2018), Interactive Playgrounds (Sturm et al., 2008), interactive open-ended play environments (Valk et al., 2012; de Valk et al., 2015) and Pervasive Games (Magerkurth et al., 2005).

APS can offer joyful, pleasant experiences, providing an entertaining pastime (van Delden et al., 2018). Furthermore, they can provide more serious benefits such as supporting a healthy lifestyle, facilitate social interaction (Bekker et al., 2010; Márquez Segura and Isbister, 2015), enhance cognitive development (Springlab Bewegend leren op de Springlab Beweegvloer voor kleuters en peuters, 2020; Hashagen et al., 2009; van Delden et al., 2018) and improve skills practice (van Delden et al., 2018).

Designers, developers and researchers are increasingly understanding how to design APS (Dalsgaard and Halskov, 2010; Dalsgaard et al., 2011; Valk et al., 2012; Márquez Segura et al., 2013; Márquez Segura and Isbister, 2015; Mueller et al., 2017), how people play (De Kort and Ijsselsteijn, 2008; Isbister, 2010; Santos, 2019), and how people interact with technology in general. But there are still many aspects to designing and implementing interactive augmented play spaces and playful interaction that we know much less about.

Much research into the design and use of APS focuses on what happens while people are playing with them. But there are preceding steps, before people are actually participating (Brignull and Rogers, 2003), that should be taken into account when these interfaces are to be implemented in situated environments. We know APS can be entertaining and stimulate positive behavior, but when no one participates-because the barrier to engage is too high, or no one understands them (Polaine, 2010)-then those benefits will never occur. Creating a seductive invitation to play is just as, or maybe even more, important than what happens after. Because, no matter how impressive the experience is that you're trying to lead people into, without a powerful invitation to play, they'll never reach that experience (Csikszentmihaly, 1990; Polaine, 2010) To be better able to achieve and demonstrate the aforementioned positive effects of APS, it is important to gain more insight in how to motivate people to engage with APS.

Based on related research, insights from previous design projects, and validation through expert interviews, we present the Participant Journey Map (PJM), providing insight into people's engagement with interactive augmented play spaces (APS) and the influential factors. Furthermore, we identify research gaps and provide suggestions for further research to better understand how to design effective and engaging Augmented Play Spaces.

\section{BACKGROUND}

An Augmented Play Space (APS) is where playful behavior and interaction emerges, facilitated by a technologically and sensory enriched, generally accessible environment. This section provides background on the aspects (semi-)Public Spaces, Augmented and Extended Reality, and Play, that come together in APS.

\section{(Semi-)Public Spaces}

APS can be part of a wide range of (semi-)public environments, both in- and outdoors and in various contexts. They can be found in many places, including indoor and outdoor playgrounds, implemented in museums and science centers, in urban settings in city squares, enriching architecture, and inside buildings, augmenting corridors and passageways a.o. These are all (semi-) public spaces with specific characteristics that distinguish them from private spaces.

Public spaces are places that are open and accessible to all people (UNESCO, 2021). They are the common physical spaces that members of a society share (Brok, 2010). Spaces that are considered to be part of public space are: roads, sidewalks, streets, public squares, parks, and beaches (UNESCO, 2021). Buildings that are generally freely accessible to the general public, are also considered to be part of public space, such as: libraries, government buildings and town halls.

Some private environments have many of the same characteristics as (truly) public environments. These semipublic spaces are places where everybody can come if they pay or have another reason of being there. Examples of semipublic spaces include indoor shopping centers and privatelyowned beaches (Vasagar, 2012), theaters, festival grounds, schools, museums, stores, train stations and amusement parks.

(Semi-)Public spaces can facilitate a variety and diversity of functions, and be places for self-expression, exchange, protest and social engagement (Harrouk, 2020). They regulate human behavior but also allow constitution and expression of individual identity (Capulong Reyes, 2016) and facilitate exposure to different types of people (Harrouk, 2020), enabling both creation and disruption of social encounters (Stavrides, 2016).

Because of their versatility, designing for (semi-)public spaces is challenging because there is a constant jumble of goals, functions, distractions and habits influencing and disrupting what people do, feel, think and notice. 


\section{Augmented and Extended Reality}

Augmented Reality (AR) in general is regarded as the phenomenon of virtual content being part of and appearing in the real world (Milgram and Kishino, 1994; Schraffenberger, 2018). Extended reality, the virtual supplementation of real environments is one of the forms of $\mathrm{AR}$ (Schraffenberger, 2018) and most relevant in the context of augmented play spaces. Spatial Augmented Reality (SAR, also known as projection mapping) is one of the manifestations of extended reality. In SAR, physical environments and/or objects are augmented without using intermediate devices (such as head mounted or handheld devices). Instead, (interactive) animations and/or images are projected, adding a virtual layer to a real environment, creating an immersive and integrated experience (Companje et al., 2006; Marner et al., 2011; Gómez-Maureira, 2014; Mast et al., 2015; van Delden et al., 2017; Mast, 2019).

Other technologies that support sensory perceptible manifestations to facilitate extended reality and spatial augmentation include screens, light (Dawson, 2019), spotlights, sound (Schraffenberger and Van Der Heide, 2014), movement (O'Toole et al., 2020), vibrations, and smell. To add interactivity, sensors can be used to register movement, touch, sound and presence, allowing the augmentations to respond to the presence and input of people (Mast et al., 2017b).

\section{Play}

Although everyone plays (Else, 2009; Sutton-Smith, 2009), knows what play is (Else, 2009) and what it feels like (Sutton-Smith, 2009)play is difficult to define (Garvey, 1990; Sutton-Smith, 2009). Play has many forms (Garvey, 1990) and although it is pleasant, it's not necessarily fun (Sicart, 2014). It can be defined as "a range of intrinsically motivated activities done for recreational pleasure and enjoyment" (Play (activity) - Wikipedia, 1990). Garvey inventories play as "pleasurable", "without extrinsic goals", "spontaneous and voluntary" and "involving some active engagement by the player" (Garvey, 1990).

Play is important and essential for our well-being, supports understanding of our surroundings and ourselves, facilitates social engagement (Sicart, 2014), and is beneficial to all people (Huizinga, 1940; Polaine, 2010). Although often associated with children, people of all ages play (Else, 2009). Play happens in all cultures (Bos, 2018) and is older than culture itself (Huizinga, 1940).

There are various conditions to enable play. Someone must have a playful (lusory) attitude (Suits, 2014) and the context and circumstances must be supportive. Although nowadays mainly used in the context of virtual gaming, the term magic circle was originally coined by Huizinga in the foundational work on play: 'Homo Ludens' (Huizinga, 1940). The magic circle can be considered as the area, moment, activity, mental state you enter when embarking on your playing journey, until you are back in the 'normal' world, picking up your daily (non-play) activities. The magic circle is where a game takes place. It might have a physical component, although many games have no physical boundaries (Salen and Zimmerman, 2003). The term magic circle is considered to be appropriate because something magical happens when play (of a game) begins (Salen and Zimmerman, 2003). In order to be able to design effective and engaging APS it is important that we understand how to get passers-by to navigate the chaotic network of influential factors and reach the 'Magic Circle.'

\section{RELATED RESEARCH}

Playful interactivity in (semi-)public spaces has been a research subject for some time, resulting in various frameworks and models providing insight into the design and use of these spaces and the behavior of participants in relation to these interactive environments. Furthermore, there is a great deal of diversity and versatility in research about interfaces in a public context and playful interfaces in general.

Some research primarily focuses on social interaction between players (De Kort and Ijsselsteijn, 2008; Gajadhar et al., 2008; Lindley et al., 2008; Isbister, 2010; Robbins and Isbister, 2014; Márquez Segura and Isbister, 2015), design principles (Parés et al., 2005; Snibbe and Raffle, 2009) or on interactivity (Salen and Zimmerman, 2003; Kultima and Stenros, 2010; Polaine, 2010; Hespanhol and Tomitsch, 2015). Other related research is more directly related and provides frameworks and models that focus on engaging people into public interfaces (Brignull and Rogers, 2003; Rogers and Rodden, 2003; Vogel and Balakrishnan, 2004; Peltonen et al., 2008; Finke et al., 2008; Müller et al., 2010; Polaine, 2010; Tieben et al., 2011; Michelis and Müller, 2011; Valk et al., 2012; Fischer and Hornecker, 2012; Memarovic et al., 2012, 2014; Bekker et al., 2014; Cheung, 2014; de Valk et al., 2015; Germany et al., 2019). In the "Insights from Related Research and Previous Design Projects" section we elaborate on related research and explain how aspects from previous research inspired the first concept of the Participant Journey Map.

Additionally, there is related work that provides background into phenomena that can influence behavior in these contexts: the 'honeypot effect' (Wouters et al., 2016); the 'peak-end rule' (Fredrickson, 2000; Kahneman, 2011; Mast et al., 2020); 'flow'(Csikszentmihaly, 1990); 'proxemics' (Marquardt, 2013; Mueller et al., 2014; McArthur, 2016); and 'interaction blindness' (Ojala et al., 2012).

Many of the models and frameworks that focus on participation are based on research of, and observations of a single or very similar interface(s). In doing so, they provide insights into that specific context, but their findings are not generally applicable. Combining insights from multiple studies, observations from multiple interfaces and analyzing previous research will lead to more substantiated insights, models and frameworks that are more widely applicable.Our work combines the diversity of insights from related research, previous design projects and knowledge of experts, attempting to lead toward a more broadly applicable model for situated augmented play spaces and providing directions for further research.

\section{RESEARCH APPROACH}

In order to gain insight into the phases and states a potential participant moves through toward engaging in augmented play 
TABLE 1 | Schematic representation of research approach.

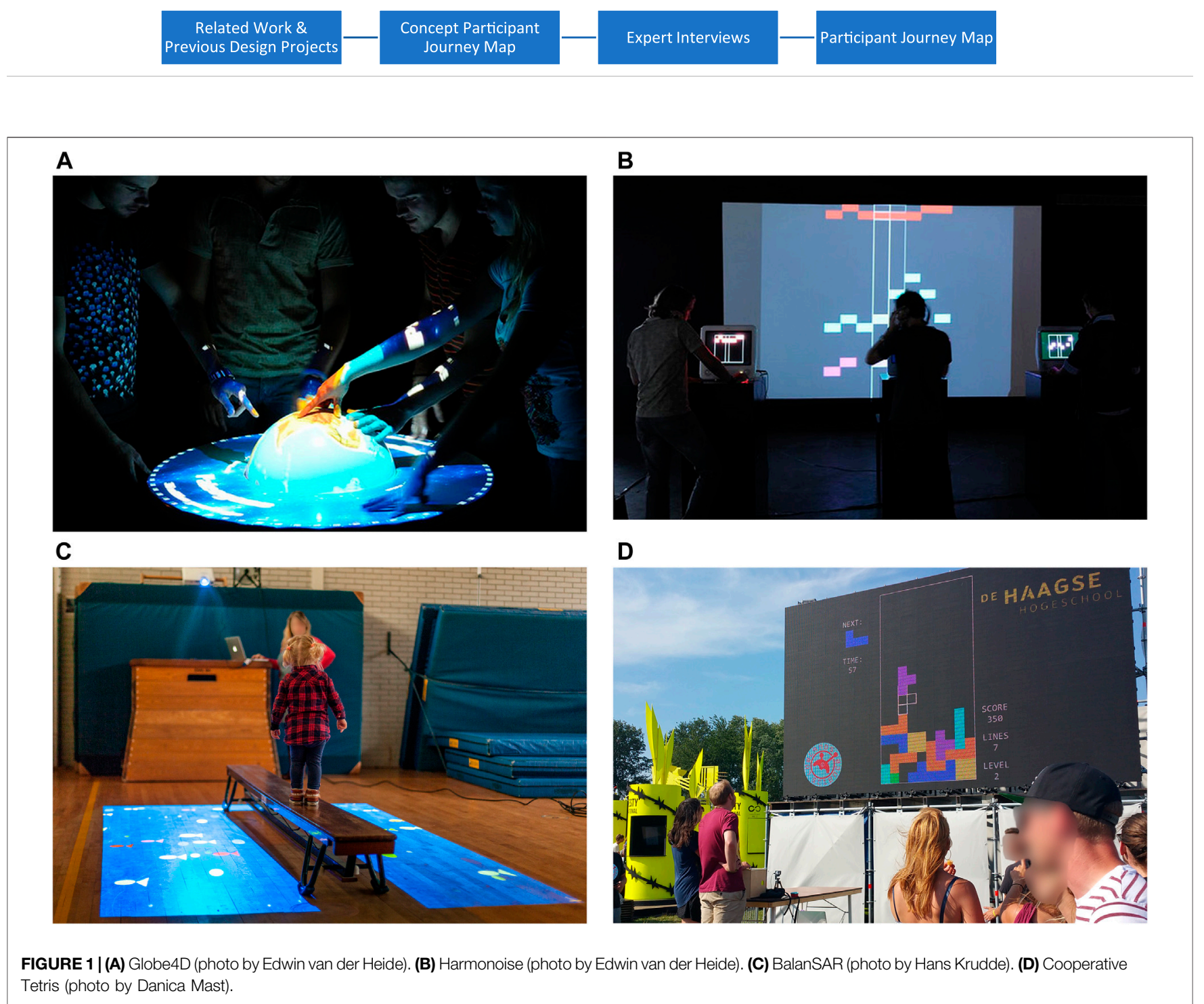

spaces and the factors that influence engagement, we first studied related work and previous APS design projects (section "Insights from Related Research and Previous Design Projects"). This resulted, through multiple iterations, in the creation of a concept version of the Participant Journey Map (PJM) (section "Concept Participant Journey Map"). Following, to validate and refine the concept version, a series of expert interviews were conducted (section "Expert Interviews"). This resulted in the design and development of the refined version of the Participant Journey Map (section "Participant Journey Map"). Table 1 illustrates this approach.

\section{INSIGHTS FROM RELATED RESEARCH AND PREVIOUS DESIGN PROJECTS}

Insights from related work and previous design projects formed the foundation for the concept Participant Journey Map. Our focus analyzing previous work and projects was on participation phases and states in relation to spatial technology-mediated interactivity in (semi-) public spaces. Six engagement states were classified and are discussed in the section "Engagement States". We first discuss the design projects that informed us briefly.

\section{Previous Design Projects}

Lessons learned from previous design projects involving APS were gathered, reviewed and summarized. These projects include the following.

Globe4D (Figure 1A) (Companje et al., 2006, 2007) is a fourdimensional globe for exploring the earth's history (e.g., continental drift), consisting of a circular table, a physically rotating outer ring and a sphere in the middle that can physically rotate in all directions. An interactive animation is projected on the sphere. Users can move the outer ring, to browse 
through earth's history and rotate the sphere to explore content from all angles. Globe4D is part of numerous temporary and continuous exhibits worldwide.

Harmonoise (Figure 1B) (V2 Lab for the Unstable Media, 2008) is an interactive art installation. Its key statement is "Disruption of personal or collective harmony in music. You influence the world around you and the world influences you... Collective harmony can only exist, if you are willing to give up certain personal desires," its focuses on the tension between altruism and egoism, and people's willingness to give up some of their personal desires for the greater good. Harmonoise consists of three music stations. Each station controls a different instrument, that can be heard on the headphones for that station. In the space where the three stations are located, all composed musical pieces are played simultaneously, sometimes creating a nuisance and a cacophony, at other times forming pleasant and interesting compositions.

BalanSAR (Figure 1C) (Mast et al., 2017a, 2017b) is developed as a research prototype and combines interactive video projections with traditional balancing exercises in Physical Education. It consists of a floor projection, augmenting balancing objects (e.g., bench, balancing stones) on the floor.

Cooperative Tetris (Figure 1D) (Mast and de Vries, 2017) has been developed as a research prototype to investigate the influence of physical activity on game experience and social interaction. A cooperative version of Tetris was developed in which the game is played by two players together. The exertion version is controlled by jumping, the passive version is controlled by pressing arcade buttons. Both variants of the input devices are novel to participants. Simultaneous actions cause rotation of the Tetris blocks, individual actions allow movement to the left or right.

These previous design projects provided valuable insights into the participation phases and states and the factors that influence engagement with APS.

\section{Engagement States}

Our analysis of literature and projects formed the foundation for the concept Participant Journey Map. Six engagement states were classified: Transit; Awareness; Interest; Intention to participate; Participation/Play and Intention to stop. Each state with their conditional influential factors is introduced and supported by insights from related work and previous design projects.

\section{Transit}

Transit is the state where a passer-by is moving from one location to another (Merriam-Webster, 2021). 'Passing by' is the action that belongs to this state of transit and is mentioned literally several times in related work (Müller et al., 2010; Michelis and Müller, 2011; Cheung, 2014; Parra et al., 2014). Other sources refer to a state of transit by using different wording: 'enter' (Finke et al., 2008), 'approach' (Germany et al., 2019), 'unoccupied' (Rubin, 2001) and 'not playing' (Moreno et al., 2012).

Experiences with previous design projects show that there are two distinct types of transit through a (semi-)public space. They relate to the reason and purpose of one's presence in that environment. In an environment such as a city square, train station or hallway in an educational building, passers-by are often in transit from one place to another with a purpose or task other than engaging with an APS. This can be considered a chance encounter. In a museum or festival environment it is often the intention of passers-by to become involved in experiences that cross their path. Often this is the main reason they are visiting that location. This can be considered a deliberate encounter.

\section{Awareness}

Once a passer-by encounters and notices an APS, they become aware of its existence and enter a state of 'awareness.' In order to become aware of the presence of an APS, they will have to notice it, therefore it has to be visible and to stand out in its surroundings. Related work mentions similar states, using various terminology, such as 'discovery' (Memarovic et al., 2012) and 'encounter' (Tieben et al., 2011).

An influential factor for entering a state of awareness is visibility, which is achieved by effective spatial and visual design. In previous design projects we learned that spatial design, together with visual design, plays an important role in gaining awareness. With Globe4D we learned that placement has an important role in the likelihood for people to become aware of its presence. Ideally the installation was placed in people's line of sight when approaching and in an environment with dimmed lighting, so that they would be more likely to notice it and the projected surfaces would stand out visually. In bright surroundings it was much more difficult to stand out. Cooperative Tetris was placed in the center of a large festival terrain, towering over the crowd, being very visible from afar. In Harmonoise, sound was used to draw attention, by playing the sound of three 'instrument stations' together in their surrounding space, resulting in something between a cacophonous or harmonious composition. Offering something novel, contrasting, or unexpected also helps to attract attention.

\section{Interest}

When someone has the opportunity, a positive lusory attitude (Suits, 2014), and is willing and curious to explore (what others are looking at, engaging with, or what the APS entails), they will enter a state of 'interest.'

Interest indicates a state where a passer-by is aware of the interface and shows interest by observing, approaching and/or standing still. The marketing model AIDA also mentions this by the term 'Interest.' Similar moments are mentioned in other work, some focusing on someone's role: 'spectator,' 'bystander,' 'observer' (Finke et al., 2008) or 'onlooker' (Parten, 1933) (Rubin, 2001), and others focusing on behavior: 'hovering' (Rubin, 2001), 'exploring' (Tieben et al., 2011), 'viewing' (Müller et al., 2010; Michelis and Müller, 2011) or 'passive engagement' (Memarovic et al., 2012).

The 'honeypot effect' is mentioned in the 'Audience funnel' framework (Michelis and Müller, 2011; Müller et al., 2010), as an influential factor of raising interest. Seeing other people interacting with an interface stimulates passers-by to approach, observe and engage too. This is behavior we also noticed in Globe4D, where people gathering around the interface and playing with it would attract others. This also occurred with Cooperative Tetris were seeing people play would attract others from afar.

A state of interest can be facilitated by design, allowing people to stand by without participating (yet). In previous design projects (Globe4D, Harmonoise, Cooperative Tetris) this was 
done by spatial placement of the installation, allowing people to observe from a distance. The circular design and central placement of Globe4D allows people to approach it from various directions. Harmonoise and Cooperative Tetris could be noticed from a distance, in Harmonoise because of its ambient/ ubiquitous sound, in Cooperative Tetris, because its large screen was visible from a distance at the festival terrain.

Other influencing factors include a passer-by's mindset and attitude toward APS or technology in general. This can be caused by previous experiences, for example with Globe4D it was noticed that people often would return and visit the installation multiple times because of positive previous experiences, wanting to explore more. With BalanSAR, on occasions with an audience interested in technology, visitors were easily interested. On other occasions where the audience was much less 'tech-savvy,' people seemed much more hesitant.

\section{Intention to Participate}

The state 'intention to participate' occurs when an interested passer-by develops a desire to participate and decides to actively engage with the interface. When someone decides to participate immediately this state can be very brief. In other cases, one has to find the right moment, look for an opportunity.

In related works this state has also been described as: 'choosing to play' (Kultima and Stenros, 2010), 'walks toward wall' (Cheung, 2014), 'desire' (AIDA), or 'potential interaction space' (Fischer and Hornecker, 2012).

An intention to participate is behavior that we have noticed in various installations. Bystanders, with the intention to participate, had to wait for a spot (Globe4D, Harmonoise, BalanSAR) or the right moment to join (Cooperative Tetris).

There are multiple factors that influence entering this state. Social dynamics play a role; in previous design projects the barrier to have the intention to participate would be much lower if friends were already participating, making it less scary and simultaneously making it attractive by showing the experience. Self-efficacy and self-confidence also play a role in this, relating to the expected usability and affordance of the APS. Interacting with an APS should give potential participants the impression it is achievable, doable, and they are capable of playing with it. This is something that was taken into account in the design of previous projects, by making technology invisible (Globe4D, BalanSAR), choosing a game that everyone knows how to play (Cooperative Tetris) or designing an easily understandable interface (Harmonoise).

\section{Participation/Play}

Participation is the state that is the ultimate and primary purpose of the participant journey. The passer-by becomes an active participant. All related work mentions this state, using various terminology, indicating specific behavior: 'active engagement' (Memarovic et al., 2012), 'explore and discover' (Cheung, 2014), 'exploration and immersion' (Valk et al., 2012; Bekker et al., 2014; de Valk et al., 2015), 'discover' (Tieben et al., 2011), 'perform gesture and observe video' (Parra et al., 2014), 'direct interaction' (Brignull and Rogers, 2003; Rogers and Rodden, 2003), 'social and cognitive play behavior' (Rubin, 2001), or 'exploration and playing' (Moreno et al., 2012).
Participation is a complex and layered activity, with its own dynamics and rules that should be captured in its own model in order to do full justice to this. In the PJM we focus on the aspects of participation that are influential for the participation journey.

In relation to participation, from previous design projects we learned many influential factors. In Globe4D, interface design and social dynamics were important factors influencing participation; a round table facilitates people to easily gather around, facing each other, motivating and stimulating conversations and facilitating social interaction. Furthermore, it was designed to evoke cooperation by allowing cooperative control, acting as a democratic interface. The table surface can rotate, influencing time in the form of continental drift. Because this is done physically, users have to make a joint decision in which direction it is moved. The same happens when interacting with the-also physically moving-sphere, people decide together which side of the globe to watch. The design ensures that users cooperate while using the interface. And because they have to reach a mutual agreement, they are in contact with each other in a playful, natural way.

In Harmonoise, interface affordance and play design were influential factors. The wall visualization of Harmonoise was designed to have an obvious relation with the composition and stations, making it clear that something can be influenced, facilitating low barrier participation. The layout of the stations was deliberately very easy to understand, lowering the barrier to engage. Each station has a screen, headphones and a mouse for selecting musical samples. The image on the screen is very basic, consisting of a moving line (indicating which sound is being played) and colored blocks. If visitors would put on headphones, they would hear one of the music channels and they could create their own composition. The navigation was designed to be intuitive, easy to understand, lowering the barrier to participate. By clicking a square, it would change color, changing or removing the instrument, rewarding exploration.

In Cooperative Tetris, opportunity and its interface and game design were influential factors. People were at a festival location, having a playful mindset and no pressing pre-occupations, enabling them to participate. It was designed to be very recognizable and comprehensible for bystanders and passers-by with understandable gameplay and rules that most people are already familiar with. Almost everyone has played Tetris at some point. It needs no explanation and requires no special skills to play, making it easily playable untrained (Mast and de Vries, 2017).

\section{Intention to Stop}

Eventually, there comes a moment at which the participant wishes or needs to stop, either voluntarily, because of external reasons or because the game ends. Most models primarily focus on facilitating and evoking engagement. With regards to ending an experience, models merely state that this occurs. In the models that do describe this state, the following wording is used: 'walks away from wall' (Cheung, 2014), 'continues on path' (Germany et al., 2019), or 'follow up actions' (Müller et al., 2010; Michelis and Müller, 2011).

None of the models specify the conditions under which this occurs, disregarding the important impact a pleasant ending could have on the overall perception of an experience 


\section{Participant Journey Map}

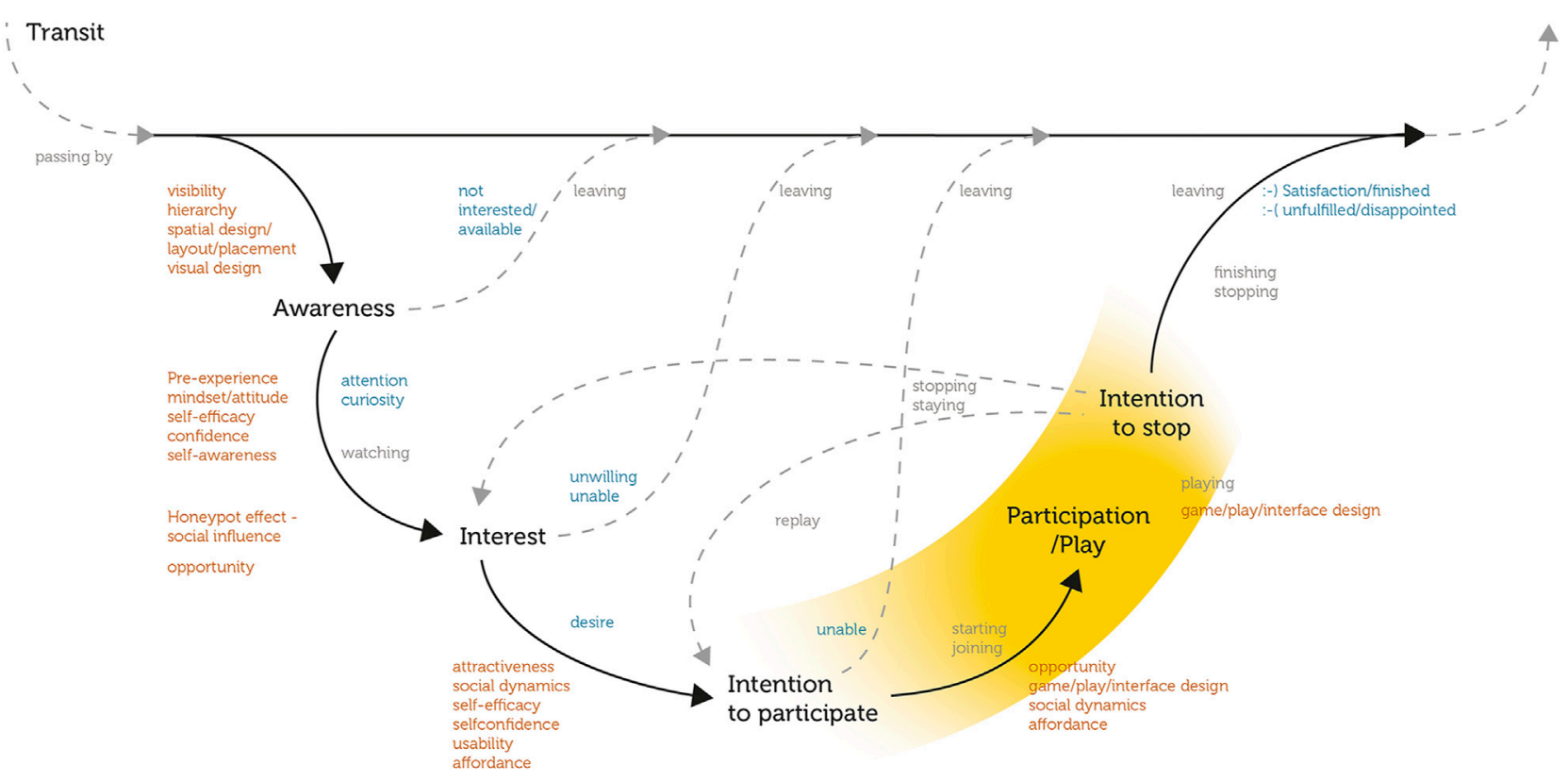

FIGURE 2 | Concept Participant Journey Map, consisting of 6 participation states: Transit; Awareness; Interest; Intention to participate; Participation/Play; Intention to stop, supported by influential factors.

(Fredrickson, 2000; Kahneman, 2011; Kane, 2018; Mast et al., 2020). We consider the end of an experience to be an important moment for a participant's attitude toward that interface or similar interfaces in the future.

Most of the previous design projects were designed to be openended-participants had the freedom to stop at any moment. People mainly seemed to stop when they had somewhere else to go or were done exploring. Cooperative Tetris was a structured game with an ending, that was decided by a timer (for research purposes). This left the participants often feeling disappointed with the sudden ending. BalanSAR has a more natural end, because participants walked from one side to the other, their participation would end when reaching the other end.

\section{Non-linearity}

So far, we have discussed the insights related to the different phases in a participation journey. An important insight, often underexposed in related research, is non-linearity. With non-linearity we mean that it is not necessary to go through all phases or states in a journey. It also refers to the ability to go back to previous states or phases.

Most participation models are linear and do not take into account that it is possible to move back and forth between phases or otherwise deviate from the default trajectory, allowing potential participants to 'skip steps.' However, some models do acknowledge forms of non-linearity. The 'Interactive Public Ambient Displays Framework' (Vogel and Balakrishnan, 2004) mentions fluid inter-phase transitions and the framework allows moving back and forth between states. The 'Stages of Playful Interaction' (Valk et al., 2012; Bekker et al., 2014; de Valk et al., 2015) also allows moving back and forth between stages. Furthermore, participants can enter the immersion stage without going through the other stages. The 'Urban HCI model' (Fischer and Hornecker, 2012) focuses on interaction spaces and mentions that people can move between roles over the course of an intervention.

Experiences with previous design projects emphasize the notion that a participation journey isn't necessarily linear and that potential participants do move back and forth between phases. This was added as a feature to the concept PJM (Figure 2).

In the PJM we regard 'states' as necessary steps toward participation. A participant always goes through them linearly, even though this can happen very quickly, in the blink of an eye. The nonlinearity in the PJM specifically refers to the fact that participants can deviate from this path when factors lead to a decision not to participate and when participants move back to previous 'states'.

\section{CONCEPT PARTICIPANT JOURNEY MAP}

Our analysis of phases and states resulted in the Participant Journey Map (Figure 2), which visualizes the participation journey. It illustrates the states, influential factors and transitions between states. The concept PJM consists of 6 participation states: 'Transit'; 'Awareness'; 'Interest'; 'Intention to participate'; 'Participation/Play'; 'Intention to stop.'

The approach of the Participant Journey Map is inspired by that of customer journey maps (Howard, 2014; Følstad and Kvale, 2018; Gibbons, 2018), a well-used tool in user experience design. 
TABLE 2 | Profiles of interviewed experts.

\begin{tabular}{|c|c|c|c|}
\hline Expert & $\begin{array}{l}\text { Years } \\
\text { active }\end{array}$ & Function & Context \\
\hline E1 & 12 & Art Director, Spatial Designer & $\begin{array}{l}\text { Festivals, Escape } \\
\text { rooms, Exhibits, } \\
\text { Theatre }\end{array}$ \\
\hline E2 & 15 & Creative Technologist & $\begin{array}{l}\text { Fairs, Festivals, Art } \\
\text { Installations }\end{array}$ \\
\hline E3 & 16 & Creative Technologist & $\begin{array}{l}\text { Festivals, Interactive } \\
\text { Outdoor Play Spaces }\end{array}$ \\
\hline E4 & 13 & Director of R\&D & $\begin{array}{l}\text { Interactive Outdoor } \\
\text { Playgrounds }\end{array}$ \\
\hline E5 & 20 & Head of Exhibits & Museum \\
\hline E6 & 16 & $\begin{array}{l}\text { Artist, Designer, Experimenter, } \\
\text { co-founder interactive design firm }\end{array}$ & $\begin{array}{l}\text { Large Augmented Play } \\
\text { Spaces, Museums }\end{array}$ \\
\hline
\end{tabular}

A 'customer journey map' is a visualization of the process that a person goes through in order to accomplish a goal (Gibbons, 2018). They offer an outline of a user's experience with a product over time (Howard, 2014).

\section{EXPERT INTERVIEWS}

Expert interviews were conducted to refine and validate the concept PJM. Expert interviews can reveal shortcomings and highlights of a concept design. They are a well-known and widely used method in design research and a way to quickly gain valuable perspective and insight into the context, background, recent findings, successes and failures in relation to a topic (IDEO, 2020). Examples of the use of expert interviews in HCI research include semi-structured expert interviews in exertion gaming research (Mueller and Isbister, 2014) and expert interviews with tangible user interface experts (Leong et al., 2017).

\section{Method \\ Participants}

The principal investigator of this study (DM) interviewed six experts [E1], [E2], [E3], [E4], [E5], [E6]. On average, the experts had over 15 years of experience, designing, developing and/or implementing playful installations in situated environments (festivals, fairs, exhibitions, museums, playgrounds, public parks, public spaces, etc.). One participant is from North America, the others from Europe. Three of the six experts have cross-continental experience. Four experts are currently active as developers and/or designers of APS, two experts are active as exhibition designers (in which playful interactivity has a prominent role) of which one is head of exhibits at a large museum. See Table 2 for expert profiles.

\section{Interviews}

One expert was interviewed in person, the others were interviewed in an online setting. The interviews took between 0:53 and 1:36 h (average: 1:09 h). Prior to the interview the experts were briefly informed in writing that the topic of the interview would be about the design and implementation of interactive play in semi-public environments. The interviews were semi-structured and consisted of two main parts: 1 -The expert's vision on phases and influential factors for engagement with APS, and 2-The expert's feedback on the concept PJM.

We started the interviews by showing the experts a sheet with a collage of pictures of augmented play spaces as a primer (Figure 3). Then, the experts were asked about the phases and factors they considered to be influential for engaging people into augmented play spaces. When needed, follow-up questions were asked to clarify answers or elicit more detailed answers, asking them about the why and how (Cooper-Wright, 2015). When the interviewer felt the general question was sufficiently answered (e.g., repeating concepts, no new issues addressed) the interview continued.

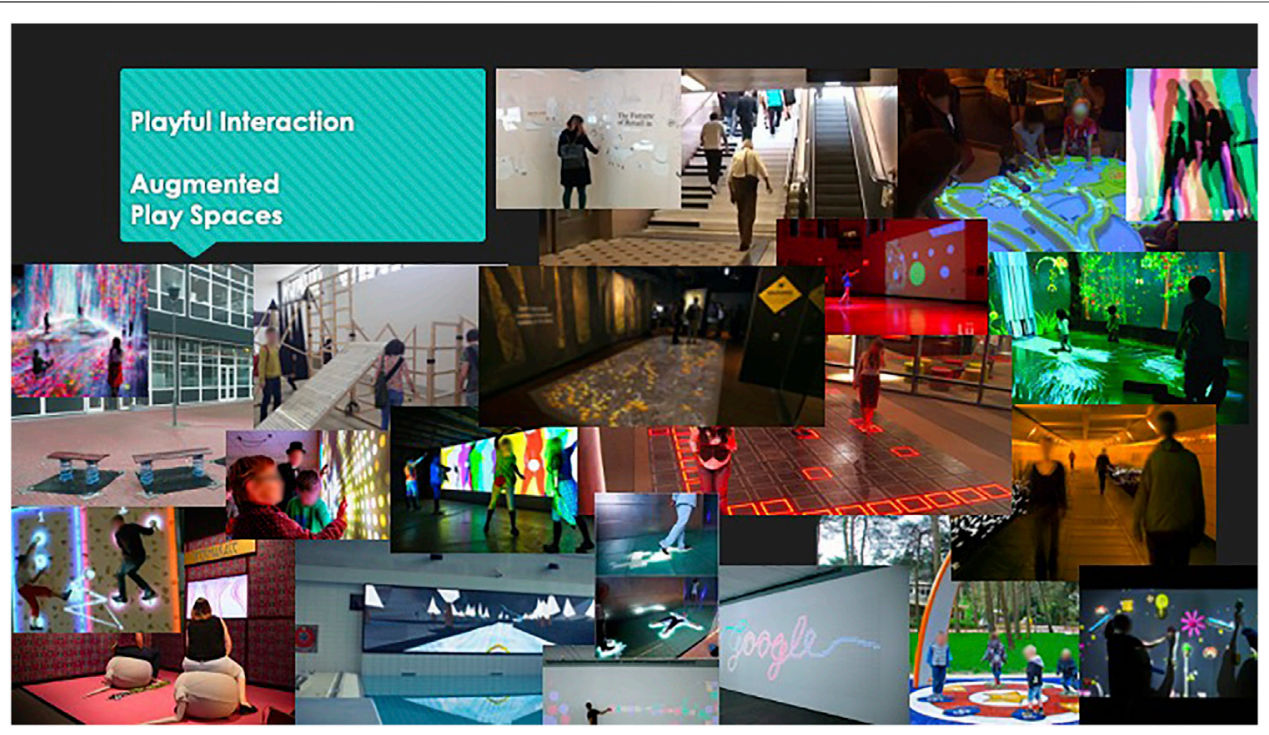

FIGURE 3 | Interview Primer: collage of APS examples. 
The second part of the interviews started by showing the experts the concept of our Participant Journey Map (Figure 2) and asking them to provide feedback.

\section{Analysis}

All interviews were coded following a combination of deductive (a priori) and inducive (emergent) coding. Coding was based on insights from the exploration of related research and previous design projects (section "Insights from Related Research and Previous Design Projects"), combined with codes for new concepts that emerged during analysis. First, all relevant quotations were marked, and initial coding was added, marking the phase, influential factors and other relevant data. Next, in multiple iterations the coding was refined, merging similar codes, subdividing them in categories and classifying them into phases, where applicable. Influential factors are classified in the phase for which they are a prerequisite.

\section{Results: Phases, States and Influential factors}

Through multiple iterations, the analysis of interview data has resulted in a detailed overview of influential factors and states of a participant journey. Table 3 shows a table with a summarized version of the expert interviews insights related to the participant journey. The results are explained per phase and state, followed by the revised PJM.

\section{Overall Feedback on Usability and Usefulness of the PJM}

The experts' reactions to the concept PJM were positive, expressing appreciation of its content and structure and recognizing what the model entails. Experts mention that they like it [E4], that "it makes sense" [E4], "it is complete" [E2][E4], recognizable [E2][E3], elegant and "(super) cool" [E6]. One expert [E2] repeatedly mentions how fascinating it is that the concept model matches their views during the first part of the interview very well, which they also find a nice confirmation for their own work.

The PJM could be useful as a (set of) guidelines for practice [E1][E2], giving insight into the considerations that should be made when designing or developing APS. The PJM could serve to indicate the broad outlines and the larger conceptual framework for implementing APS, providing guidance on the steps to follow for your own specific implementation [E2].

TABLE 3 | Summary of insights from the expert interviews, related to the participant journey.

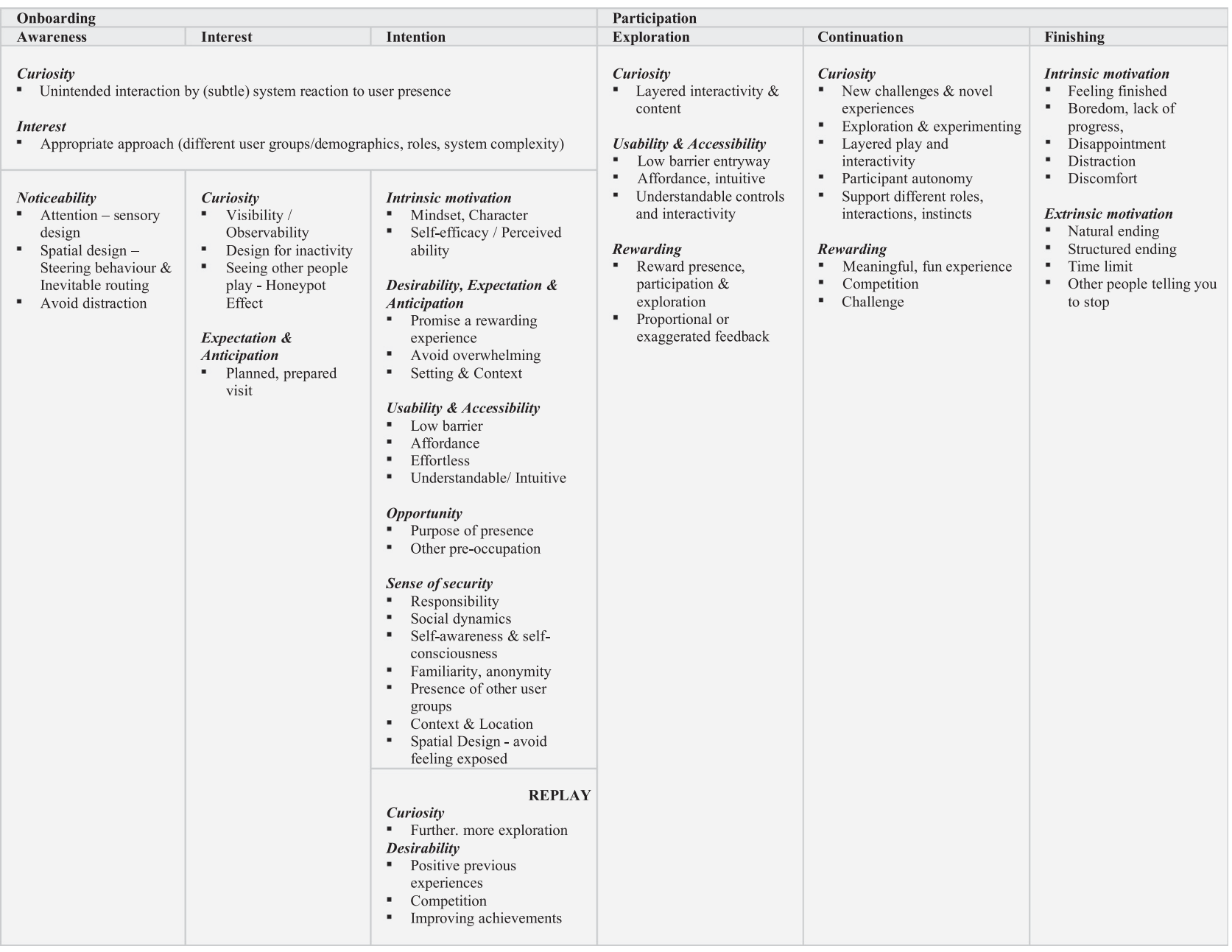


One expert [E5] remarks that in order for the PJM to be useful for them and other professionals, the usability of its design should be improved. Making it clearer what the goal and core message of the model is. Another expert [E4] likes that the participation phase is highlighted in orange, emphasizing what they mention as being 'the core.'

\section{Onboarding}

A number of experts made statements about influential factors that relate to (a combination of) steps or states ('Awareness,' 'Interest' and 'Intention') that lead to participation. This is mentioned as onboarding multiple times by one of the experts [E6]. We decided to regard onboarding as a distinct phase and include it as an overarching phase in the revised PJM.

Although 'onboarding' is previously defined in the context of gaming/playing by Petersen et al. as "The first few minutes of play" (Petersen et al., 2017), in the PJM 'onboarding' is regarded as the process of getting someone on board of the APS, including the preceding actions and steps. This is more in line with commonly used definitions of onboarding, such as "the act or process of familiarizing a new customer with one's products or services" (Merriam-Webster, 2020) and (more corporate) "the process in which new employees gain the knowledge and skills they need to become effective members of an organization" (Onboarding, 2020). It also relates to (transportation) "to go aboard (a vessel, train, aircraft, or other vehicle)" (Board definition and meaning, 2021) and (nautical) boarding: "to come alongside (a vessel) before attacking or going aboard" (Board - definition and meaning, 2021). These definitions all consider onboarding or going on board as the steps or actions preceding the entity that will be boarded, leading to boarding it. Therefore, in the PJM, we regard onboarding as the steps and activities leading to getting on board the APS.

Onboarding in the PJM involves the processes of encountering an APS, noticing it, becoming curious, getting closer, taking the decision to participate leading to exploration.

For some APS, 'Awareness,' 'Interest' and 'Intention' can seem to take place almost simultaneously in just a few seconds [E1]. Experts indicate curiosity and interest through an appropriate approach as influential factors relating to onboarding. Different user groups need slightly different onboarding approaches [E6] and there has to be something to experience for people in every role (waiting, observing, playing) [E3]. Additionally, a complex system should have a well thought out, tailored onboarding, whereas a simple system can have a simpler onboarding [E6].

Curiosity can be evoked by a subtle reaction of a system to user presence [E1][E2][E4]. For example, when they walk underneath an interface, and something happens [E4]. This can be an unintended action by the passer-by. This type of system reaction to user presence is also an effective way to inform a passer-by about the presence of an interactive system when no one is playing [E1]. One expert mentions that letting people participate unknowingly, could lead to making them feel they are lured in [E5] and should be considered very carefully. This subtle, unexpected and unintended interaction can be incorporated in an APS (to draw attention) under the condition that does not put the focus of attention on that individual specifically [E5].

\section{Awareness}

Awareness, the first state of onboarding, can be described as the knowledge that something exists (Awareness Meaning Cambridge English Dict, 2021) and is the state someone reaches once they have encountered and noticed the APS. Based on analysis of the expert interviews, combined with what we already found in related research and previous design projects we conclude that noticeability is a key influential factor for this state.

To gain awareness, an APS has to be noticed by passers-by. Therefore, it should be designed to stand-out [E4], attracting attention. This can be achieved by the use of sound and visual design (e.g., markers, lighting). Distraction (by irrelevant things) should be avoided [E1]. Spatial design (e.g., object placement, sight lines, lighting, routing) can steer user behavior to stimulate an encounter [E1]. Inevitable routing can make it almost impossible to walk past without noticing its interactivity [E1] [E6] and can avoid giving people room for a way out when passing by [E1].

\section{Interest}

Interest, the second state of the onboarding phase is mainly driven by curiosity. To become curious, people need to have the opportunity to observe the APS. Visibility and observability can be achieved by effective spatial, visual and interface design. An APS should be specifically designed for an idle/inactive situation without play, when the first user approaches [E1]. A playful installation can be made to look interesting when no one is playing by showcasing a demo or letting staff play [E3].

People already playing attract others [E4]. This corresponds with the previously mentioned honeypot effect (Brignull and Rogers, 2003; Wouters et al., 2016). Design of an APS should allow people to observe what others are doing [E1][E5][E6]. People like to observe first, design should facilitate a space to be near the installation without being in it [E6].

Preparation and expectation are other influential factors. When a passer-by expects to encounter an APS, they will be prepared and more likely to show interest. A planned visit evokes expectation [E5]. A visitor's expectations can be primed before visit (buying ticket, routing) or by hearing about it from others [E1].

\section{Intention}

The intention (to participate) is the state someone reaches when they are aware of the APS, interested and have decided (the intention) to participate. Entering this state is influenced by a mix of intrinsic, extrinsic, contextual and design factors.

According to the experts, someone's willingness to engage partly depends on their character and mindset [E1], intrinsic factors. Some people are self-conscious and naturally not or less likely to engage [E4][E5]. They might think playing is not for them (or their demographic) [E4]. Or they are worried about breaking things, unsecure and don't dare to participate [E4]. Other people are naturally curious and interested and have no fear or hesitation to participate [E3][E4][E5]. 
Anticipation and expectation also influence the intention to participate. It is important for a potential visitor to get an impression of what to expect. It should be clear what the reward of participation is [E1]. A promise of a positive experience or reward makes it desirable for potential participants. For example, seeing other(s) having fun lowers the barrier to want to try and engage [E1][E2][E5]. This can also be achieved by an APS that promises a magical experience [E6]. Also, a long queue raises the expectation that the APS must be worthwhile [E3].

Evoking an expectation of something less desirable might discourage participation. Therefore, an APS should not seem too wild and crazy [E6], have too much visible technology (screens, lights, sounds) or be too overwhelming, because that puts people off [E4]. There is a higher barrier to participate when no one is playing yet [E1], because it's not clear what to expect.

The purpose of presence and the opportunity that arises from it also influences someone's willingness to participate. When someone is pre-occupied with something else (e.g., work, grocery shopping, catching a train) the barrier to participate is high [E1]. At a later moment (e.g., during drinks after work) that willingness may be there [E3], because their purpose of presence has shifted (e.g. done working), giving them opportunity.

To engage people in a setting where they are likely to have an external preoccupation (e.g., shopping center), it must be taken into account in the design of an APS that they don't want to wait but want to be able to do something immediately. In a casual, leisurely setting (e.g., festival) participants don't mind waiting [E3].

Participation should seem to require little mental and physical effort. An APS should be accessible for any age and ability [E6], have a low barrier physical design [E4] and be designed for the lowest common denominator [E6]. It should not take too much effort before being rewarded [E6]. For example, asking people to hook up devices, such as VR-sets [E6] and embodied sensors, or to fill in too much information upfront [E6] should be avoided.

This also related to the importance of good affordance of an APS; people should understand the interaction [E3] and what they can and should do with the system [E1][E5]. The interface should appear intuitive, not complicated, not time-consuming upon first impression [E2].

Self-efficacy, someone's perceived ability also plays a role herein-how good does someone think they will be at playing? [E5]. Ideally, participation should not require special skills [E4], because practice is needed for gaining skills, raising the barrier to participate. APS (games) that rely on tactics have a low barrier, because practice is not required to perform well [E3].

According to the experts, the social dynamics is another influential factor for the intention to participate and relates to a sense of security. People should feel secure to start participating [E5].

Seeing others having fun lowers the barrier to want to try and engage [E1][E2], because of the aforementioned expectation it rises and because it makes people feel less vulnerable, compared to playing alone. On the other hand, other user groups participating (e.g., bigger kids, adults, other demographic) might give people the feeling it's not for them [E6]. Such is also the case for regular playground games [E4]. For example, kids feel vulnerable when many adults are already playing [E6] and might decide not to join while initially and/or actually wanting to join.

The location and setting of an APS are influential factors for the willingness of passers-by to engage with them. One expert explains that at a large music festival there is a certain anonymity, there's little fear of standing out, and visitors have a playful, open mindset [E3]. At a local village festival, or a business fair, there is a fear of standing out because everyone knows you [E3]. At these locations, the threshold for visitors to participate is much higher because of a fear of failure (in front of acquaintances). However, another expert mentions something seemingly opposite. An encounter in a space with only strangers being present raises the barrier [E1] whereas an encounter in a space with friends or family lowers the barrier to participate [E1]. Especially teenagers are naturally shy; they feel more secure when they can do something as a group [E6]. An any case, the degree of familiarity and anonymity seems to be an influential matter.

This also relates to people feeling insecure about participation because they are afraid of being laughed at by others [E3], they don't want to be made fun of [E5]. One expert explains that it should not stand out to others that you (as a player) are responsible for certain activity [E5]. Single player games have a higher barrier to participate because the player is individually responsible for the result [E3]. Multiplayer games have a lower participation barrier [E1] because participants share responsibility for the result [E3].

When you participate, you become a performer [E5], but not everyone feels comfortable being watched. Effective spatial design can make people feel less vulnerable. Creating a dark playing environment and avoiding bright environments with people watching [E6] helps to achieve this. Other solutions are to let people play alone with no bystanders (although this has many other undesirable effects) or facilitate crowded anonymity [E1] (creating a crowded environment where participants feel anonymous). VR can also make people feel vulnerable: you don't know who's watching and what they might be doing to you without you noticing [E2].

Inviting people to participate is complicated. Create a safe comfortable setting and avoid pushing or explicitly inviting them to participate [E1][E3]. Avoid petrifying potential participants by directly addressing them. Instead, nudge them playfully [E3] and let people make a conscious decision to engage [E5].

\section{Intention: Replay}

So far, the intention to participate focused on the situation of a first encounter. However, when someone considers playing again (after temporarily stopping or re-encountering an APS), specific factors influence the intention to replay-participate again.

Curiosity facilitates the desire to play again (next time) and can be evoked by finding out there is more to explore [E2]. This can be achieved by providing room to observe after play to enable discovery of new unexplored content [E2] and making each time someone participates different. 
Competition is another factor that can affect willingness to replay. The urge to improve your previous or someone else's score [E3][E4] can be a motivating factor to come back. Although a personal experience with a simple, meaningful interface is worth more than winning with a complex interface [E2].

People are always influenced by what they know or experienced before [E1]. A memory of a positive previous experience with an APS (or similar interface) [E1] influences the intention to participate. Therefore, a previous encounter should have evoked a meaningful personal experience [E5].

\section{Participation}

The participation phase is the ultimate goal of the participation journey. Based on the results of the expert interviews this phase includes the states exploration, continuation and finishing.

\section{Exploration}

Participation starts with exploration. This state is facilitated by the influential factors: curiosity, usability and reward.

To enable participation, the APS should be designed to have an inviting, low barrier [E1], obvious and easy entryway [E6]. Affordance is important, the installation should be intuitive [E1] and not time-consuming to consider or understand [E2]. An APS design should be intuitive to use, clearly indicating the choices that can be made [E5] and what to do with the system [E1]. Furthermore, form and/or experiences should indicate functionality instead of explicitly explaining functionality [E4][E6].

Interactivity and content should be layered [E6], supporting curiosity. When a user steps in, an APS should take you onboard a story [E5] and reward participation and exploration [E4]. It should be immediately clear that it's interactive and that their presence has impact [E6]. The APS should react immediately/promptly to user presence [E6] and input [E4]. Start with minimal required input, the more comfortable participants get, the less selfconscious and shy they will feel and the more they can commit to the experience [E6]. Once participants understand it is interactive, allow them to explore and tease out other interactive things [E6]. Desirable actions should be rewarded instead of enforced [E6]. Any movement should elicit a system response, giving proportional or exaggerated feedback [E6]. Following, there can be less intuitive interaction, still fairly easy to discover and often related to the first interactions [E6]. Ending with the possibility for in-depth, complex experiments [E2], with interactive elements that take longer to discover but create a layer of magic [E6], leading to continued participation.

\section{Continuation}

After a participant has explored interacting with the APS, they will enter a state of continuation. The main factors influencing this state of continuation are curiosity, which is facilitated by novelty, exploration, autonomy, variety and versatility, and offering rewarding objectives.

According to the experts, an APS should support many different roles and interactions, speaking to different instincts [E6]. Ensure that an experience continues to be fun by matching a participant's realm of experience [E4] and allow them to give meaning to their experience [E5]. To keep it interesting, an APS should give a participant autonomy [E6]. This can be done by allowing them to go through structured content at a chosen speed [E2], allowing them set new targets [E5], giving them control over level choice, letting them explore new things [E4] and allowing experimentation [E2]. Furthermore, an APS should adjust difficulty and challenge to user skills and progress [E4], giving the user a feeling of improvement [E5].

Participation can be extended by facilitating amorphic and emergent play [E6]. This can be done by offering the participant variety [E5]: new challenges [E2][E4][E5], novel experiences [E2] [E4] and layered complexity [E6]. Continuously bringing a participant in a new play state and dosing their frustration [E5] is another effective way of elongating participation. Although competition (facilitated by a scoring system) can also be an effective trigger goal [E3].

One expert mentions that the quality of an experience should be the goal, not the duration [E2]. This indicates that not in all circumstances elongated continuation should be a core objective of an APS.

\section{Finishing}

Finishing or the intention to stop is the final state of participation. Experts recognize it when they see it suggested in the PJM concept, remarking that it makes sense and is very elegant [E6]. One expert also mentions that what happens after someone is done playing is often overlooked [E1].

The intention to stop can be fueled by intrinsic motivators: feeling finished [E1], the impression to have gotten as much out of it as possible [E6], boredom [E4][E5], lack of progress [E5], disappointment because of mismatched expectations [E3], distraction [E6][E4] and physical discomfort [E6]. Other motivators are external: time is up [E5][E6], parents telling kids to go [E4][E6] or players having the feeling they're not playing for themselves anymore, but for the audience or maker(s) [E5].

Play can have a structured, closed ending or an unstructured open ending. Closed ended play provides more structure [E4] than open ended play, but offers less room for exploration, experimentation and player autonomy. Open endedness is very nice, and allows for exploration, but it can also cause player interest to fade when implemented wrong [E4]. Open endedness should not be an excuse for not having to design structure, as this might result in players not finding it interesting at all [E4]. Successful open-ended games often still offer a lot of structure, providing many rules, but also shouldn't determine too much [E4]. Another expert explains that successful unstructured play needs to be layered and leveled [E6].

An APS can prompt participants to end their participation by having a natural ending (time is up, story is finished, game over) to a structured game [E1], a designed obvious ending (dark screen, movie stops, end of space) [E1], because the story ends [E5], or by creating a natural ending to an unstructured game (e.g., day-night cycle to indicate end of day) [E6]. 
An experience should end in a positive way. Whatever happens, celebrate the end and avoid a sad ending [E3]. Afterward, people will remember things that did not work well or responded differently than expected. Negative experiences linger longer [E1]. When an experience is overwhelmingly awesome or great, the end becomes less important and flaws during the experience will matter less [E1]. One expert mentions finding it challenging to design a peaking ending, because there are so many moments when someone can stop [E4]. Another expert mentions that in general museums (consider to be play experiences in their entirety) lack in giving visitors a sense of completion at the end of a visit [E5]. One expert mentions that an experience can be purposely designed to evoke a feeling of frustration or disappointment, when those feelings are a predetermined (and essential) part of the experience [E2]. This applies, for example, to more artistic works with the aim to convey a message, to make people think through a specific experience or an emotion.

A scoring system as an objective, although effective [E3] is also considered to be very blunt and in the end there will always be a winner and a loser [E5]. Therefore, evoking a meaningful, magical experience [E1] might be a better objective goal to ensure a positive ending [which is important for the intention to play with similar systems (section "Intention Replay") and replay with the same system (section "Intention Replay")].

\section{Other Results}

In the previous section, we discussed the results of the interviews related to participation stages, states, and influencing factors of the PJM. The interviews also revealed additional results relating to the context of the participant journey. These results are described in this section.

\section{Chronology and Time Frame}

Although most influential factors happen during a visit, some can take place prior to a visit [E1]. This may be because someone has prepared for a visit, creating anticipation and expectation. Someone usually plans a visit to a museum or festival, and the visitor knows more or less what to expect. Here the preparation plays an important role in creating expectation and anticipation, influential factors for entering states of Interest and Intention.

While most encounters happen during one visit, a participant journey can also take place over the course of several encounters. Where 'awareness' takes place during an earlier visit than 'intention to participate.' It is suggested to be useful to mention this in relation to the PJM [E1].

An example of such a situation is when someone encounters 'the piano stairs' - an interactive staircase in a station (Review Piano Stairs - Beyond Social, 2020) that plays piano sounds when you walk over it. They may come across this APS while trying to catch the train, not having the opportunity to pay much attention to it. On a subsequent visit, that time might be there, and they remember noticing the piano stairs previously, but not having the opportunity then and decide to pay attention now. In this case, the participant journey is spread over a time frame of several visits.

Another expert mentions that the faster someone can go through the phases; the smaller chances are that they will disengage [E2]. When people have the chance to think too long, they might choose not to try. When there are more conscious steps to take, it becomes easier to decide not to follow through.

\section{Non-linearity}

Multiple positive remarks were made [E6] about the PJM having loops back to previous phases. Emphasizing that people need space to stop interacting, process what they've experienced and make the decision whether they're really done playing or want to play more. They mention that there are definitely cycles occurring in a participation journey and remark that building for those cycles is a very good way to approach interaction design [E6]. Another expert mentions they appreciate the feedback loop from 'intention' to 'interest' and recognize that this often happens [E4]. They give the example of kids stopping, watching how others are playing and decide to continue playing or play again. One expert mentions that (although undesirable) it's very recognizable that there are four possible moments when someone can decide to leave before participation [E1].

\section{PARTICIPANT JOURNEY MAP}

The revised version of the Participant Journey Map (PJM) (Figure 4) combines the insights from related research and previous design projects (section "Insights from Related Research and Previous Design Projects") (that formed the foundation for the concept PJM (Figure 2, section "Concept Participant Journey Map") with the input and feedback of experts (section "Expert Interviews").

The Participant Journey Map consists of four layers: Phases, States, Transitions and Influential Factors. There are two overarching phases: 'Onboarding' and 'Participation' and 6 states a (potential) participant goes through when engaging with an APS: 'Transit,' 'Awareness,' 'Interest,' 'Intention,' 'Participation,' 'Finishing.' When passers-by go through the process to engage with an APS, they transition between different states. This includes transitions resulting from decisions not to partake in an APS (leaving or remaining an observing bystander) or to revisit a previously experienced state (finished playing and becoming a spectator again or waiting until there is opportunity to participate again). Transitions are affected by influential factors.

\section{Adaptations and Preservations Compared to the Concept PJM}

Based on insights from the expert interviews, the Participant Journey Map was refined and updated. The original structure was largely maintained.

The state of transit was maintained, although this was not explicitly mentioned by or discussed with the experts. However, no comments were made in the interviews about the presence of this state in the PJM, it appeared to be taken for granted and considered to be obvious.

An overarching phase 'Onboarding' was added, under which the already existing states 'Awareness,' 'Interest' and 'Intention to 


\section{Participant Journey Map}

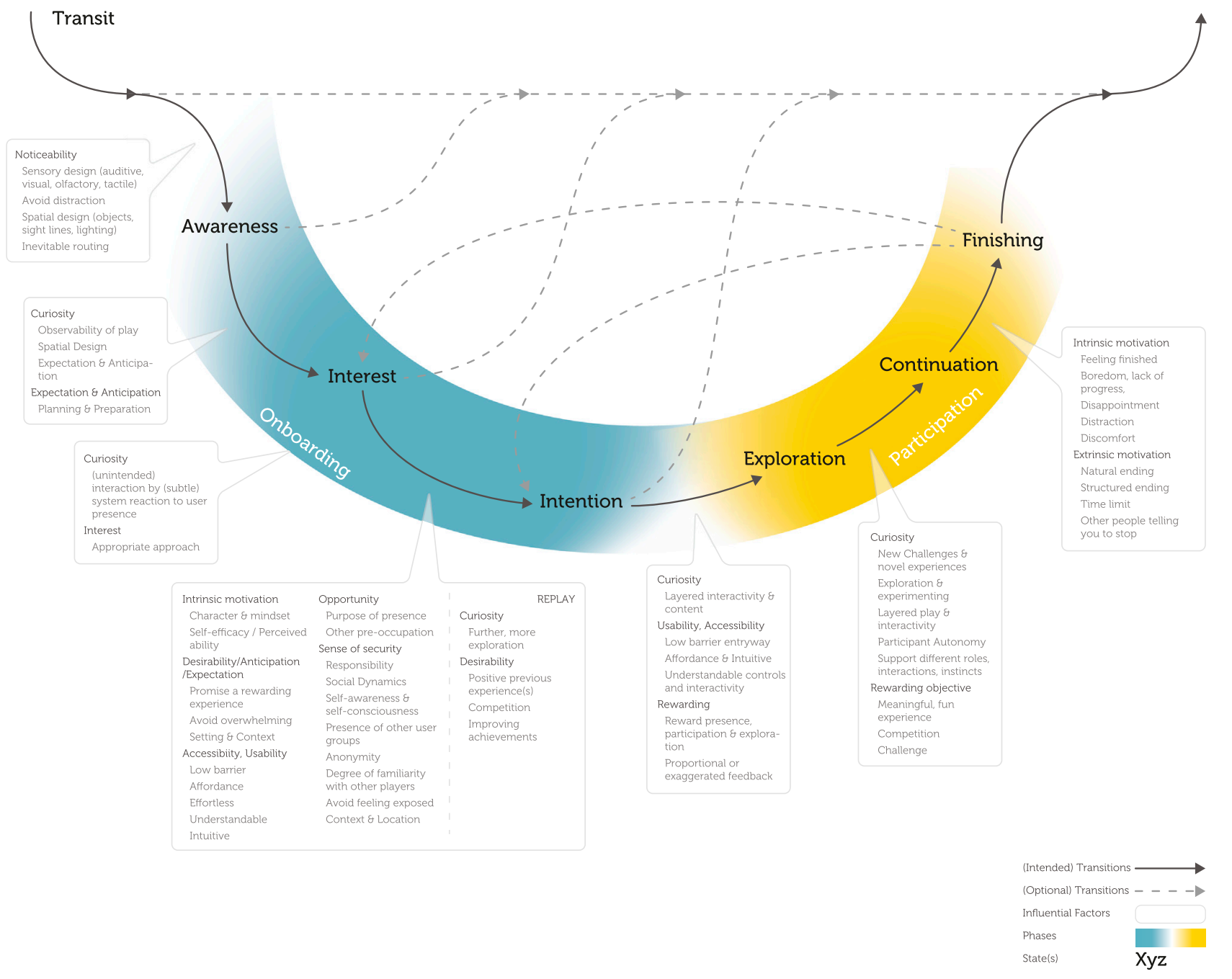

FIGURE 4 | Participant Journey Map.

participate' are placed. It flows into the state of 'Exploration' of the 'Participation' phase. This is in accordance with one of the experts explicitly mentioning onboarding as a phase and other experts indicating that these states often happen in a flow.

The 'Participation' phase was (visually) emphasized, within which the states 'Exploration,' 'Continuation' and 'Finishing' are placed. This structure emphasizes that what happens within these phases can occur in a flow of events, where it can be difficult to distinguish sub-states. Also, some influential factors mentioned by experts relate to the series of events that occur in a phase like onboarding as a whole and don't relate to just one of the substates.

'Exploration' is a newly added state. The interviews indicated that this is a separate state during participation with its own characteristic features. The state of 'Finishing' was renamed (previously Intention to stop). This better describes that a participant is in a state of completion of participation at that moment.

A distinction is no longer made between different types of influencing factors. They turned out to be so diverse in terms of cause and underlying reasons that they proved too complex to classify into categories.

The journey directions were maintained, still allowing nonlinear movement through the model. Influential factors were updated, according to expert input as explained in the section "Expert Interviews".

The PJM was visually improved. Colored bands were emphasized for the overarching phases, making it clearer that the underlying states flow into each other. The contrast of the 
'transit' line was decreased, since this is an undesired (optional) route and should therefore not be emphasized visually.

\section{DISCUSSION AND DIRECTIONS FOR FUTURE RESEARCH}

In this section we provide an overview of notable findings and directions for further research. This includes ambiguities, research gaps, emerged questions and interesting findings that are promising to further look into.

\section{Design for Inactivity}

Experts indicate that an APS should be designed specifically for a situation of inactivity. When no one is playing yet it should still be able to attract attention, create the right expectation of its experience and how to interact with it. A way to do this is by showcasing play (Tieben, 2015) or directly trying to elicit interaction (Parker and Tomitsch, 2017; Parker, 2018).

Related research and design primarily focus on how to design for participation but tend to overlook that the majority of the time an APS will be in a state of inactivity. While, when an APS is implemented in a semi-public environment, this is a key moment leading toward eventual participation. More research is needed to better understand how to design for inactivity and be better able to effectively implement APS in situated environments.

\section{Clear Expectations vs. a Magical Experience}

An APS should have a low barrier entryway, the affordance of an APS should be apparent quickly and it should be very clear to an observer what experience to expect. But participation with an APS should also be surprising and evoke a magical feeling (Reeves et al., 2005; Reeves, 2011). How can a truthful expectation be achieved without giving away all the magic?

\section{Annoying vs. Enticing Unintended Interaction}

Opinions of experts toward incidental interaction when passing by were twofold. Some suggest making a system react to a passer-by not yet aware of the system and hereby provoking awareness and a reaction. However, it was also mentioned that this might cause an adverse reaction, evoking a feeling of selfawareness in passers-by and giving them the feeling of being lured in. Further research could tell where the line is between unintentional interactivity being annoying or enticing.

\section{Visibility of Play: Attraction vs. Barrier}

Experts mention that an APS and current participants, should be clearly visible for potential players (Dalton et al., 2010; Akpan et al., 2013). Visibility of people playing attracts others, the honeypot effect (Brignull and Rogers, 2003; Wouters et al., 2016), and offers an expectation of the experience that awaits someone once they decide to participate. Also, the promise of playing with other people lowers the sense of vulnerability during play because of joint responsibility. On the other hand, strangers and people with a different demographic raise the barrier to participate. This can be caused by social barriers and feelings of exclusion ("it's not for me"). Furthermore, experts indicate that participants shouldn't feel being observed or watched, because this makes them feel vulnerable and self-conscious. This presents an interesting paradox regarding the visibility of play. It provides a challenge to better understand how to design an APS and its context in such a way that it is visible while avoiding giving current players a vulnerable, unsecure feeling by being watched. Further research is needed to understand the variables that play a role in the attractiveness vs. the barrier of visibility of play and how APS visibility can facilitate the most fluent participant journey.

\section{Familiarity with Potential Co-Players and the Audience}

Experts suggest that the degree of familiarity with people already playing or that they will potentially play with, influences one's willingness to engage into a situation where people are already playing. It is suggested that presence of good friends or family lowers the barrier. Experts experienced that when the audience consists of people that know you, but that you don't feel completely at ease with (co-workers, neighbors) raises the barrier to participate. Whereas they experience that complete anonymity lowers the barrier.

Further research on the influence of familiarity on the barrier to engage, will support understanding of how to design APS that are effective for different social circumstances. Familiarity with potential co-players and people watching should also be taken into account when designing experimental setups, as this can influence people's engagement.

\section{Influence of Previous Experiences on Willingness and Recurrent Play}

An experience is often regarded as just that occurrence. An experience however already starts before a visit, (long) before the actual activity starts. The journey leading toward an experience influences how someone approaches an APS, their mindset and attitude. This relates to someone's previous positive experiences with the same (aka. recurrent play Tieben et al., 2013; Tieben, 2015) or similar systems. But also to expectations that are based on their attitude toward interactive technology in general, which is influenced by all previous experiences with similar technology. Little is known about the influence of these pre-encounter influences and how to support recurrent play. Future research should take this into account.

\section{Design for Any Ability and Level of Competence}

A design approach for interfaces is usually user-centered, focusing on a specific audience. One of the experts mentions that an APS should be designed for any ability and level of competence [E6]. This seems contradictory, however, considering that APS are implemented in public environments where all kinds of people pass by and there often isn't a specific 
user group, designing for a broad audience makes sense. To allow APS to be effective in these contexts it must appeal to a broad audience with a various range of skills and interests. It remains to be seen it is feasible to design for any ability and level of competence while keeping the APS interesting, challenging and doable for all users.

\section{Play-Mindedness}

One aspect that is occasionally briefly mentioned but that we have not emphasized yet is differences in behavior and experience with respect to play. This is highlighted for example between children and adults. Based on the interviews, related work and design projects there are indications that these different groups behave in different ways. Children have a much more open mindset, wanting to try and experiencing little barriers. Adults often think that playing is not for them, while playfulness is also beneficial to them. This is something to take into account in future research. An interesting approach would be to design APS that works for multiple user groups with different levels of play-mindedness.

\section{Democratic Interfaces}

Group dynamics play an important role in how people use and experience an APS. The way people jointly use an interface is then determined by social cohesion, dynamics and hierarchy. How can we design democratic, social (Isbister, 2010; Moreno et al., 2012; van Delden, 2012), cooperative (Parés et al., 2005; Robbins and Isbister, 2014) interfaces-that facilitate joint decision making?

\section{Structure}

Open ended (de Valk et al., 2015), unstructured-and-closed ended, structured play have different characteristics. Open ended, unstructured play facilitates fulfilling curiosity by allowing exploration and giving a participant autonomy. Closed ended, structured play allows setting clear goals. How can an unstructured APS be designed to give participants autonomy, but also ensure that they perform certain actions, perform desired behavior and acquire intended knowledge? And how can autonomy and exploration be facilitated in structured APS? It is interesting for future research to investigate the characteristics of successful structured and unstructured APS, to better understand how to implement these aspects. This is highly related to the paradox of open world games in the digital gaming field.

\section{Leveled and Layered Interactivity and Content}

Experts emphasize that layered and leveled interactivity and content is important for prolonged and recurrent participation. Including these aspects into an APS design can support feelings of curiosity and challenge, both motivators for the willingness to play longer, or again (Tieben, 2015). Many current APS however have quite shallow game designs. How to incorporate this and to what extent is a topic for further research.

\section{Positive Ending (and Memory) of Play}

Ending play and how to facilitate a positive ending to play is a still under-researched topic. Most research and design projects focus on how to achieve participation and what happens during participation and how to design for this. But generally, HCI design and research, tends to overlook that there's also something that happens when someone is done participating. Something that could possibly even be a key aspect influencing a remembered experience (Fredrickson, 2000; Kahneman, 2011; Kane, 2018; Mast et al., 2020), and therefore evoking a positive attitude toward participation and replay in future encounters with the same or similar systems. This is something that is valuable for $\mathrm{HCI}$ researchers and practitioners to focus on in future research.

\section{Applicability to Other Fields}

We suspect that the Participant Journey Model is also applicable to other types of human computer interaction such as game development, human-robot interaction, and e-health/m-health. We see many opportunities to explore in future research what the similarities and differences are between participant journeys for various interfaces. Because it takes into account the pre-experience and ending of an experience, the PJM can provide interesting perspectives for exploring participant journeys in other contexts.

\section{CONCLUSION}

In this article we presented the Participant Journey Map (PJM). The PJM illustrates the journey a potential participant takes when encountering an augmented play space, and the factors that influence their decisions during this journey.

The PJM was developed following multiple iterations. Based on related work, and insights gained from previously developed and implemented APS, a first concept of the PJM was developed. Following, interviews with 6 experts with extensive experience with developing and implementing APS were conducted. The first part of these interviews focused on influential (design) factors for engaging people into APS. In the second part, experts were asked to provide feedback on the first concept of the PJM. Based on the insights from the expert interviews, the Participant Journey Map was adjusted and refined.

The Participant Journey Map provides insight into people's engagement with interactive augmented play spaces and the influential factors facilitating their journey. It consists of four layers: Phases, States, Transitions and Influential Factors. There are two overarching phases: Onboarding and Participation and 6 states a (potential) participant goes through when engaging with an APS: Transit, Awareness, Interest, Intention, Participation, Finishing. When passers-by go through the process to engage with an APS, they transition between states. Transitions are affected by influential factors.

The PJM contributes to previous work by providing a detailed overview of a participant journey and the factors that influence motivation to engage with APS.

Notable additions to previous research are (1) a detailed insight into factors that influence decision making of people encountering an APS and (2) providing a structured overview of the phases and states a potential participant goes through on their participation journey. In particular the introduction 
of the states 'Awareness,' 'Intention' and 'Finishing' and the non-linear approach are novel compared to other models. Especially 'Awareness' and 'Finishing' will support taking into account these often overlooked, key moments in APS research and design projects.

Our work provides a basis for future research, contributing to a better understanding of designing Augmented Play Spaces and the implementation of playful interaction in (semi-)public spaces. At the same time the Journey map gives directions for design and implementations of APS.

\section{DATA AVAILABILITY STATEMENT}

The datasets presented in this article are not readily available because, they contains information that can be traced back to individuals. Requests to access the datasets should be directed to “d.mast@hhs.nl”.

\section{ETHICS STATEMENT}

Ethical review and approval was not required for the study on human participants in accordance with the local legislation and institutional requirements. Written informed consent was not

\section{REFERENCES}

Akpan, I., Marshall, P., Bird, J., and Harrison, D. (2013). "Exploring the effects of space and place on engagement with an interactive installation," in Conference on Human Factors in Computing Systems-Proceedings, New York, NY: ACM Press, 2213-2222. doi:10.1145/2470654.2481306

Awareness Meaning Cambridge English Dict. (2021). Available at: https://dictionary. cambridge.org/dictionary/english/awareness (Accessed February 24, 2021).

Bekker, T., De Valk, L., and Eggen, B. (2014). A toolkit for designing playful interactions: The four lenses of play. J. Ambient Intell. Smart Environ. 6, 263-276. doi:10.3233/AIS-140259

Bekker, T., Sturm, J., and Eggen, B. (2010). Designing playful interactions for social interaction and physical play. Pers Ubiquit Comput 14, 385-396. doi:10.1007/ s00779-009-0264-1

Board - definition and meaning Collins English Dict. (2021). Available at: https:// www.collinsdictionary.com/dictionary/english/board (Accessed March 26, 2021).

Bos, M (2018). Spelen is bloedserieus, als je naar de gezichten in "De Spelende Mens" kijkt| Trouw. Available at: https://www.trouw.nl/nieuws/spelen-is-bloedserieus-als-je-naarde-gezichten-in-de-spelende-mens-kijkt b5a398cd/ (Accessed December 14, 2020).

Brignull, H., and Rogers, Y. (2003). Enticing People to Interact with Large Public Displays in Public Spaces. Interact 14, 17-24. doi:10.1145/2757710.2776803

Brok, J. (2010). De onzichtbare openbare ruimte: exploratief onderzoek naar de ontwikkeling van het beleidsdomein openbare ruimte. London: Markdal.

Capulong Reyes, R. (2016). Public Space as Contested Space: The Battle over the Use, Meaning and Function of Public Space. Ijssh 6, 201-207. doi:10.7763/ IJSSH.2016.V6.643

Cheung, V. (2014). "Improving interaction discoverability in large public interactive displays," in ITS 2014-Proceedings of the 2014 ACM International Conference on Interactive Tabletops and Surfaces, New York, NY: Association for Computing Machinery, Inc, 467-472. doi:10.1145/2669485.2669489

Companje, R., Van Dijk, N., Hogenbirk, H., and Mast, D. (2006). Globe4D, Proceedings of the 14th annual ACM international conference on Multimedia-MULTIMEDIA’06, New York, NY: ACM, 959-960. doi:10. $1145 / 1180639.1180850$ provided because participants provided recorded verbal consent to participate in this study and to their data being used.

\section{AUTHOR CONTRIBUTIONS}

DM was the principal investigator for this study and responsible for the study design, conducting the review of related work and previous design projects, conducting and analyzing the expert interviews and designing the Participant Journey Model. JB, SV and FV supervised and supported all research activities and contributed to the manuscript revisions. All authors reviewed and approved the final manuscript.

\section{FUNDING}

This Ph.D. research is funded by the Dutch Research Council (NWO) doctoral Grant for teachers (023.013.062).

\section{ACKNOWLEDGMENTS}

We would like to thank the experts for volunteering their time to participate in the interviews.

Companje, R., Van Dijk, N., Hogenbirk, H., and Mast, D. (2007). “Globe4D, timetraveling with an interactive four-dimensional globees," in SIGGRAPH '07: ACM SIGGRAPH 2007 emerging technologies, New York, NY: ACM, 26.

Cooper-Wright, M. (2015). The Importance of How and Why in a Design Research Interview. Medium. Available at: https://medium.com/design-research-methods/ the-importance-of-how-and-why-4560bf7ae488 (Accessed June 3, 2020).

Csikszentmihaly, M. (1990). Flow: The Psychology of Optimal Experience. London: Harper \& Row.

Dalsgaard, P., Dindler, C., and Halskov, K. (2011). Understanding the dynamics of engaging interaction in public spaces. Lect. Notes Comput. Sci. 6947, 212-229. doi:10.1007/978-3-642-23771-3_17

Dalsgaard, P., and Halskov, K. (2010). Designing urban media façades. Conf. Hum. Factors Comput. Syst. Proc. 4, 2277-2286. doi:10.1145/1753326.1753670

Dalton, S. N., Marshall, P., and Dalton, R. C. (2010). "Measuring environments for public displays," in Conference on Human Factors in Computing Systems-Proceedings, New York, NY: ACM, 3841-3846. doi:10.1145/ 1753846.1754066

Dawson, C. S. (2019). 'Olafur Eliasson: In Real Life' Review: A Shallow Experience. Medium. Available at: https://medium.com/c.shepdaw/olafur-eliasson-in-reallife-review-a-shallow-experience-ba0435bac4la (Accessed April 12, 2021).

De Kort, Y. A. W., and Ijsselsteijn, W. A. (2008). People, places, and play. Comput. Entertain. 6, 1-11. doi:10.1145/1371216.1371221

de Valk, L., Bekker, T., and Eggen, B. (2015). Designing for social interaction in open-ended play environments. Int. J. Des. 9, 107-120. doi:10.4108/icst. intetain.2015.259742

Else, P. (2009). The value of play. Dallas, TX: Continuum.

Finke, M., Tang, A., Leung, R., and Blackstock, M. (2008). "Lessons learned," in DIMEA, Proceedings-3rd International Conference on Digital Interactive Media in Entertainment and Arts, New York, NY. ACM Press, 26-33. doi:10.1145/1413634.1413644

Fischer, P. T., and Hornecker, E. (2012). "Urban HCI," in Conf. Hum. Factors Comput. Syst.-Proc., New York, NY: ACM Press, 307-316. doi:10.1145/ 2207676.2207719

Følstad, A., and Kvale, K. (2018). Customer journeys: a systematic literature review. Jstp 28, 196-227. doi:10.1108/JSTP-11-2014-0261 
Fredrickson, B. L. (2000). Extracting meaning from past affective experiences: The importance of peaks, ends, and specific emotions. Cognit. Emotion 14, 577-606. doi:10.1080/026999300402808

Gajadhar, B., de Kort, Y., and IJsselsteijn, W. (2008). "Influence of social setting on player experience of digital games," in Proceeding of the twenty-sixth annual CHI conference extended abstracts on Human factors in computing systems-CHI'08, New York, New York. ACM Press, 3099. doi:10.1145/ 1358628.1358814

Garvey, C. (1990). in Play. Editor B. Lloyd (Cambridge: Harvard University Press). doi:10.2514/6.1990-3679

Germany, J. O., Speranza, P., and Anthony, D. (2019). Eliciting Public Display Awareness and Engagement: An Experimental Study and Semantic Strategy. Int. J. Human-Computer Interact. 35, 1975-1985. doi:10.1080/10447318.2019.1597572

Gibbons, S (2018). "Journey Mapping 101. Nielsen Norman Gr," Available at: https:// www.nngroup.com/articles/journey-mapping-101/ (Accessed December 3, 2020).

Gómez-Maureira, M. A. (2014). Illuminating Shadows: Introducing Shadow Interaction in Spatial Augmented Reality. ChiSparks 11, 33. doi:10.1109/ ismar-adjunct.2016.0062

Harrouk, C. (2020). Public Spaces: Places of Protest, Expression and Social Engagement | ArchDaily. ArchDaily. Available at: https://www.archdaily.com/941408/public-spacesplaces-of-protest-expression-and-social-engagement (Accessed December 14, 2020).

Hashagen, A., Büching, C., and Schelhowe, H. (2009). "Learning Abstract Concepts through Bodily Engagement: A Comparative, Qualitative Study," in Proceedings of the 8th International Conference on Interaction Design and Children-IDC '09, New York, NY. ACM Press. doi:10.1145/1551788.1551839

Hespanhol, L., and Tomitsch, M. (2015). Strategies for intuitive interaction in public urban spaces. Interact. Comput. 27, 311-326. doi:10.1093/iwc/iwu051

Howard, T. (2014). Journey Mapping: A Brief Overview. Available at: http://www. adaptivepath.com/ideas/theanatomyofan (Accessed December 3, 2020).

Huizinga, J. (2008). Homo ludens: Proeve eener bepaling van het spel-element der cultuur. tweede her. Amsterdam: H. D. Tjeenk Willink \& Zoon N.V. - Haarlem. doi:10.5117/9789089640031

IDEO (2020). Design Kit. Available at: https://www.designkit.org/methods/43 (Accessed December 16, 2020).

Isbister, K. (2010). Enabling Social Play: A Framework for Design and Evaluation. Evaluating User Experience in Games. London: Springer, 11-22. doi:10.1007/ 978-1-84882-963-3_2

Kahneman, D. (2011). Thinking, fast and slow. New York, NY: Farrar, Straus and Giroux.

Kane, L. (2018). The Peak-End Rule: How Impressions Become Memories. Nielsen Norman Gr. Available at: https://www.nngroup.com/articles/peak-end-rule/ (Accessed December 18, 2019).

Kultima, A., and Stenros, J. (2010). "Designing games for everyone," Future Play 2010: Research, Play. Share-International Academic Conference on the Future of Game Design and Technology, 66-73. doi:10.1145/1920778. 1920788

Leong, J., Perteneder, F., Jetter, H.-C., and Haller, M. (2017). What a Life!. TEI 2017-Proceedings of the 11th International Conference on Tangible, Embedded, and Embodied Interaction, Yokohama. Association for Computing Machinery, Inc., 57-66. doi:10.1145/3024969.3024985

Lindley, S. E., Le Couteur, J., and Berthouze, N. L. (2008). Stirring up experience through movement in game play. Conf. Hum. Factors Comput. Syst. Proc. 7, 511-514. doi:10.1145/1357054.1357136

Magerkurth, C., Cheok, A. D., Mandryk, R. L., and Nilsen, T. (2005). Pervasive games. Comput. Entertain. 3, 4. doi:10.1145/1077246.1077257

Marner, M. R., Smith, R. T., Porter, S. R., Broecker, M. M., Close, B., and Thomas, B. H. (2011). Large Scale Spatial Augmented Reality for Design and Prototyping. in Handbook of Augmented Reality. New York: Springer, 231-254. doi:10.1007/978-1-4614-0064-6_10

Marquardt, N. (2013). Proxemic interactions with and around digital surfaces. ITS 2013-Proceedings of the 2013 ACM International Conference on Interactive.New York, NY: Tabletops and Surfaces, 493-494. doi:10.1145/2512349.2512354

Segura, E. M., and Isbister, K. (2015). Enabling Co-Located Physical Social Play: A Framework for Design and Evaluationin Game User Experience Evaluation. Berlin: Springer, 209-238. doi:10.1007/978-3-319-15985-0_10

Márquez Segura, E., Waern, A., Moen, J., and Johansson, C. (2013). The design space of body games. Conf. Hum. Factors Comput. Syst. Proc. 15, 3365-3374. doi:10.1145/2470654.2466461
Mast, D. (2019). "Social interaction in spatial augmented exertion interfaces," in CHI PLAY 2019-Extended Abstracts of the Annual Symposium on Computer-Human Interaction in Play. London: Association for Computing Machinery, Inc., 29-34. doi:10.1145/3341215.3356331

Mast, D., Bosman, M., Schipper, S., and De Vries, S. (2017a). "BalanSAR," in TEI 2017-Proceedings of the 11th International Conference on Tangible, Embedded, and Embodied Interaction. London: Association for Computing Machinery, Inc., 625-631. doi:10.1145/3024969.3025085

Mast, D., Bosman, M., Schipper, S., Diederiks, S., and de Vries, S. (2017b). "Adding Interactivity to BalanSARACM," in Extended Abstracts Publication of the Annual Symposium on Computer-Human Interaction in Play. New York, NY, USA: ACM, 383-389. doi:10.1145/3130859.3131327

Mast, D., de Krom, J., and de Vries, S. (2015). Exploring the Application of Interactive Video Projection in Physical Education. Proceedings of the Ninth International Conference on Tangible, Embedded, and Embodied Interaction. New York, NY, USA: ACM, 551-555. doi:10.1145/2677199.2687901

Mast, D., and de Vries, S. (2017). "Cooperative tetris: The influence of social exertion gaming on game experience and social presence," in Lecture Notes of the Institute for Computer Sciences, Social-Informatics and Telecommunications Engineering, LNICST. Berlin: Springer Verlag, 115-123. doi:10.1007/978-3-319-49616-0_11

Mast, D., Vries, D., Broekens, J., Verbeek, F., Vries, S. D, Broekens, J., et al. (2020). The importance of the peak-end rule for repeated visits to Augmented Play Spaces Persuasive 2020 Adjunct Proceedings (Aalborg, Denmark). Available at: http://ceurws.org/Vol-2629/8_poster_mast.pdf (Accessed December 14, 2020).

McArthur, J. A (2016). Digital proxemics : how technology shapes the ways we move. Available at: https://dl.acm.org/doi/abs/10.5555/3027590 (Accessed April 8, 2021). doi:10.3726/978-1-4539-1724-4

Memarovic, N., Gehring, S., Fischer, P. T., Fischer, T., and Fischer, P. T. (2015). ELSI Model: Bridging User Engagement around Interactive Public Displays and Media Facades in Urban Spaces. J. Urban Technol. 22, 113-131. doi:10.1080/ 10630732.2014.942169

Memarovic, N., Langheinrich, M., Alt, F., Elhart, I., Hosio, S., and Rubegni, E. (2012). "Using public displays to stimulate passive engagement, active engagement, and discovery in public spaces," in Proceedings of the 4th Media Architecture Biennale Conference on Participation-MAB'12. New York, NY: ACM Press, 55-64. doi:10.1145/2421076.2421086

Merriam-Webster Onboarding (2021). Definition. Available at: https://www. merriam-webster.com/dictionary/onboarding (Accessed March 26, 2021a).

Merriam-Webster Transit (2020). Definition. Merriam-Webster. Available at: https:// www.merriam-webster.com/dictionary/transit (Accessed August 4, 2020b).

Michelis, D., and Müller, J. (2011). The Audience Funnel: Observations of Gesture Based Interaction With Multiple Large Displays in a City Center. Int. J. Human-Computer Interact. 27, 562-579. doi:10.1080/10447318. 2011.555299

Milgram, P., and Kishino, F. (1994). A Taxonomy of Mixed Reality Visual Displays Using Stereoscopic Video for Defence Teleoperation, IEICE Trans. Inf. Syst. 77. Available at: http://vered.rose.utoronto.ca/people/paul_dir/IEICE94/ieice.html (Accessed April 11, 2021), 1321-1329.

Moreno, A., van Delden, R., Reidsma, D., Poppe, R., and Heylen, D. (2012). An annotation scheme for social interaction in digital playgrounds. in Lecture Notes in Computer Science (including subseries Lecture Notes in Artificial Intelligence and Lecture Notes in Bioinformatics) (Springer), 85-99. doi:10. 1007/978-3-642-33542-6_8

Mueller, F., and Isbister, K. (2014). "Movement-based game guidelines," in Conference on Human Factors in Computing Systems-Proceedings. New York, NY, USA: Association for Computing Machinery), 2191-2200. doi:10. 1145/2556288.2557163

Mueller, F., Stellmach, S., Greenberg, S., Dippon, A., Boll, S., Garner, J., et al. (2014). "Proxemics play," in Proceedings of the Conference on Designing Interactive Systems: Processes, Practices, Methods, and Techniques. London: DIS (Association for Computing Machinery), 533-542. doi:10.1145/2598510.2598532

Mueller, F. F., Gibbs, M. R., Vetere, F., and Edge, D. (2017). Designing for bodily interplay in social exertion games. ACM Trans. Comput.-Hum. Interact. 24, 1-41. doi:10.1145/3064938

Müller, J., Alt, F., Michelis, D., and Schmidt, A. (2010). "Requirements and Design Space for Interactive Public Displays," in MM'10-Proceedings of the ACM Multimedia 2010 International Conference. New York, NY: ACM, 1285-1294. doi:10.1145/1873951.1874203 
O’Toole, M., Ratcliff, A., Charnas, I., and Witte, A. (2020). About the Waterfall Swing-Waterfall Swing. Available at: https://www.waterfallswing.com/about (Accessed April 12, 2021).

Ojala, T., et al. (2012). Multipurpose Interactive Public Displays in the Wild: Three Years Later. Computer 45 (5), 42-49.

Onboarding (2020). Definition Cambridge English Dict. Available at: https://ictionary. cambridge.org/dictionary/english/onboarding (Accessed March 26, 2021).

Parés, N., Durany, J., Carreras, A., and Carreras, A. (2005). "Massive flux design for an interactive water installation," in ACE '05: Proceedings of the 2005 ACM SIGCHI International Conference on Advances in computer entertainment technology, New York: NY: ACM, 266-269. doi:10.1145/1178477.1178523

Parker, C. (2018). Augmenting Space: Design approaches for making public interactive displays relevant in hyperconnected societies. Available at: https://ses.library.usyd.edu. au/handle/2123/18993. doi:10.1145/3205873.3205889

Parker, C., and Tomitsch, M. (2017). Bridging the interaction gulf. ACM Int. Conf. Proceeding Ser. 14, 482-486. doi:10.1145/3152771.3156162

Parra, G., De Croon, R., Klerkx, J., and Duval, E. (2014). "Quantifying the interaction stages of a public display campaign in the wildFun, Fast, Foundational," in Proceedings of the NordiCHI 2014: The 8th Nordic Conference on Human-Computer Interaction, New York: NY: ACM, 757-760. doi:10.1145/2639189.2639216

Parten, M. B. (1933). Social play among preschool children. J. Abnormal Soc. Psychol. 28, 136-147. doi:10.1037/h0073939

Peltonen, P., Kurvinen, E., Salovaara, A., Jacucci, G., Ilmonen, T., and Evans, J. (2008). "It's Mine, Don't Touch!," in Conference on Human Factors in Computing Systems-Proceedings, New York: NY: ACM, 1285-1294. doi:10.1145/1357054.1357255

Petersen, F. W., Thomsen, L. E., Mirza-Babaei, P., and Drachen, A. (2017). "Evaluating the Onboarding Phase of Free-toPlay Mobile Games," in CHI PLAY 2017-Proceedings of the Annual Symposium on Computer-Human Interaction in Play, New York: NY: ACM, 377-388. doi:10.1145/3116595.3125499

Play activity - Wikipedia Wikipedia (1990). Available at: https://en.wikipedia.org/ wiki/Play (Accessed April 20, 2021).

Polaine, A. (2010). Developing a Language of Interactivity Through the Theory of Play. Thesis (PhD). Available at: $\mathrm{http}: / /$ hdl.handle.net/10453/20225 (Accessed July 10, 2020).

Reeves, S. (2011). A Framework for Designing Interfaces in Public Settings. Des. Interfaces Public Settings 33, 141-175. doi:10.1007/978-0-85729-265-0_8

Reeves, S., Benford, S., O’Malley, C., and Fraser, M. (2005). "Designing the spectator experience CHI 2005: Technology, Safety, Community," in Conference Proceedings-Conference on Human Factors in Computing Systems. New York, NY: Association for Computing Machinery, 741-750. doi:10.1145/1054972.1055074

Review Piano Stairs - Beyond Social. (2020). Available at: https://beyond-social. org/wiki/index.php/Review_Piano_Stairs (Accessed December 20, 2020).

Robbins, H., and Isbister, K. (2014). "Pixel Motion: A Surveillance CameraEnabled Public Digital Game," in Proceedings of Foundations of Digital Games. New York, NY: Association for Computing Machinery.

Rogers, Y., and Rodden, T. (2003). "Configuring Spaces and Surfaces to Support Collaborative Interactions." in Public and Situated Displays. Dordrecht: Springer, 45-79. doi:10.1007/978-94-017-2813-3_3

Rubin, K. H. (2001). The Play Observation Scale (POS). Dordrecht: Springer.

Salen, K., and Zimmerman, E. (2003). Rules of Play: Game Design Fundamentals. Cambridge: MIT Press.

Santos, C. P. (2019). Understanding People through Games. Available at: https:// pure.tue.nl/ws/portalfiles/portal/127357625/20190624_Pereira_Santos.pdf.

Schraffenberger, H. K. (2018). Arguably augmented reality: relationships between the virtual and the real. Available at: https://hdl.handle.net/1887/67292

Schraffenberger, H., and Van Der Heide, E. (2014). "The real in augmented reality," in Proceedings of the Second Conference on Computation, Communication. London: Aesthetics and $\mathrm{X}, \mathrm{xCoAx}$.

Sicart, M. (2014). Play Matters. MIT Press. doi:10.7551/mitpress/10042.001.0001

Snibbe, S. S., and Raffle, H. S. (2009). "Social immersive media," in Conference on Human Factors in Computing Systems-Proceedings. New York, NY: ACM Press, 1447-1456. doi:10.1145/1518701.1518920

Springlab Bewegend leren op de Springlab Beweegvloer voor kleuters en peuters (2020). Available at: https://springlab.nl/ (Accessed December 20, 2020).

Stavrides, S. (2016). Common Space: The City as Commons. London: Zed Books. doi:10.5040/9781350219267
Sturm, J., Bekker, T., Groenendaal, B., Wesselink, R., and Eggen, B. (2008). "Key issues for the successful design of an intelligent, interactive playground," in Proceedings of the 7th international conference on Interaction design and children-IDC '08. New York, NY: ACM Press, 258. doi:10.1145/1463689. 1463764

Suits, B (2014). The Grasshopper-: Games, Life and Utopia. Cambridge: Broadview Press. Sutton-Smith, B. (2009). The ambiguity of play. Cambridge: Harvard University Press.

Tieben, R. (2015). Activating Play-A design research study on how to elicit playful interaction from teenagers. Available at: https://research.tue.nl/files/3857195/ 798382.pdf

Tieben, R., Bekker, T., and Schouten, B. (2011). "Curiosity and interaction: Making people curious through interactive systems," in Proceedings of HCI 2011-25th BCS Conference on Human Computer Interaction, New York, NY: ACM Press, 361-370. doi:10.14236/ewic/hci2011.66

Tieben, R., Sturm, J. A., Bekker, M. M., and Schouten, B. A. M. (2013). Eliciting Recurring Curiosity Through Playful Interactions. Berlin: Springer.

UNESCO Inclusion Through Access to Public Space (2021). United Nations Educ. Sci. Cult. Organ. Available at: http://www.unesco.org/new/en/social-andhuman-sciences/themes/urban-development/migrants-inclusion-in-cities/ good-practices/inclusion-through-access-to-public-space/ (Accessed February 9, 2021).

V2 Lab for the Unstable Media. (2008). Media Technology MSc exhibition-six years of creative research. Available at: https://v2.nl/events/media-technologymsc-exhibition (Accessed March 26, 2021).

Valk, L. D., Rijnbout, P., Bekker, T., Eggen, B., Graaf, M. D., and Schouten, B. (2012). "Designing for playful experiences in open-ended intelligent play environments," in Proceedings of the IADIS International Conference Game and Entertainment Technologies. New York, NY: ACM Press, 3-10.

van Delden, R. (2012). "Towards a socially adaptive digital playground," in ACM International Conference Proceeding Series. New York, NY: ACM Press, 355-358. doi:10.1145/2307096.2307166

van Delden, R., Gerritsen, S., Heylen, D., and Reidsma, D. (2018). Colocated augmented play-spaces: past, present, and perspectives. J. Multimodal User Interfaces 12, 225-255. doi:10.1007/s12193-0180269-z

van Delden, R., Moreno, A., Poppe, R., Reidsma, D., and Heylen, D. (2017). “A Thing of Beauty," in Conference on Human Factors in Computing Systems-Proceedings. London: Association for Computing Machinery, 2462-2472. doi:10.1145/3025453.3025816

Vasagar, J. (2012). Privately owned public space: where are they and who owns them? |News|The Guardian. Guard. Available at: https://www.theguardian. com/news/datablog/2012/jun/11/privately-owned-public-space-map (Accessed November 20, 2020).

Vogel, D., and Balakrishnan, R. (2004). "Interactive public ambient displays," in Proceedings of the 17th annual ACM symposium on User interface software and technology-UIST '04, New York, NY: ACM Press. doi:10.1145/1029632. 1029656

Wouters, N., Downs, J., Harrop, M., Cox, T., Oliveira, E., and Webber, S. (2016). "Uncovering the Honeypot Effect," in DIS 2016-Proc. 2016 ACM Conf. Des. Interact. Syst. Fuse, New York, NY: ACM Press. 5-16. doi:10.1145/2901790. 2901796

Conflict of Interest: The authors declare that the research was conducted in the absence of any commercial or financial relationships that could be construed as a potential conflict of interest.

Copyright $\odot 2021$ Mast, de Vries, Broekens and Verbeek. This is an open-access article distributed under the terms of the Creative Commons Attribution License (CC $B Y)$. The use, distribution or reproduction in other forums is permitted, provided the original author(s) and the copyright owner(s) are credited and that the original publication in this journal is cited, in accordance with accepted academic practice. No use, distribution or reproduction is permitted which does not comply with these terms. 